\title{
Monetary Union with a Single Currency and Imperfect Credit Market Integration
}

\author{
Vincent Bignon1, Régis Breton² and Mariana Rojas Breu ${ }^{3}$
}

\begin{abstract}
This paper shows that currency arrangements impact on credit available through default incentives. To this end we build a symmetric two-country model with money and imperfect credit market integration. With the Euro Area context in mind, we capture differences in credit market integration by variations in the cost for banks to grant credit for cross-border purchases. We show that for a high enough level of this cost, currency integration may magnify default incentives, leading to more stringent credit rationing and lower welfare than in a regime of two currencies. The integration of credit markets restores the optimality of the currency union.
\end{abstract}

JEL: E42, E50, F3, G21

Keywords: banks, currency union, monetary union, credit, default

1 Banque de France and Economix at Uniersité Paris Nanterre. DGEI-Demfl-Pomone 41-1422; 31 rue Croix des Pétits champs; 75001 Paris, France.

E-Mail: vincent.bignon@banque-france.fr

2 Banque de France. E-Mail: regis.breton@banque-france.fr

3 Université Paris Dauphine. E-Mail: mariana.rojas-breu@dauphine.fr 



\title{
Monetary Union with A Single Currency and Imperfect Credit Market Integration*
}

\author{
Vincent Bignon ${ }^{\dagger}$ \\ Banque de France
}

\author{
Régis Breton ${ }^{\ddagger}$ \\ Banque de France and CNRS
}

\author{
Mariana Rojas Breu ${ }^{\S}$ \\ Université Paris Dauphine
}

First version: October 2013

This version: February 5, 2015

\begin{abstract}
This paper shows that currency arrangements impact on credit available through default incentives. To this end we build a symmetric two-country model with money and imperfect credit market integration. With the Euro Area context in mind, we capture differences in credit market integration by variations in the cost for banks to grant credit for cross-border purchases. We show that for a high enough level of this cost, currency integration may magnify default incentives, leading to more stringent credit rationing and lower welfare than in a regime of two currencies. The integration of credit markets restores the optimality of the currency union.

Keywords: banks, currency union, monetary union, credit, default.

J.E.L. codes: E42, E50, F3, G21
\end{abstract}

*For helpful comments, we thank Viral Acharya, Philippe Andrade, David Andofaltto, Luis Araujo, Valerie Bencivenga, Aleksander Berentsen, Renaud Bourlès, Jean Cartelier, Laurent Clerc, Michael Bordo, Hubert Kempf, Antoine Martin, Julien Matheron, Raoul Minetti, Benoit Mojon, Ed Nosal, Albrecht Ritschl, Guillaume Rocheteau, Eugene White and seminar participants at SKEMA Business School, Basel Universität, Banque de France, Banco Central de la República Argentina, University Paris Nanterre, the 2013 French economic association meeting, the 2013 conference of Society for the Advancement of Economic Theory, the 2013 Asociación Argentina de Economía Política, the 2014 Royal Economic Society Meeting, the 2014 Journées LAGV, the 2014 IFABS conference, the 2014 Chicago Fed Summer Workshop in Money, Banking and Finance, the 2014 London Money, Macro and Finance conference, the 2014 Vienna FIW conference and the 2015 ASSA-AEA meeting. This paper circulated previously with the title "Currency Union with and without Banking Union". Jocelyne Tanguy provided outstanding assistance with graphs. The views expressed herein are those of the authors and not necessarily those of the Banque of France or the Eurosystem.

${ }^{\dagger}$ Banque de France and EconomiX at Université Paris Nanterre. Email: vincent.bignon@banque-france.fr; DGEI-Demfi-Pomone 41-1422; 31 rue Croix des Petits Champs; 75001 Paris France.

${ }^{\ddagger}$ Banque de France. Email: regis.breton@banque-france.fr; DGO-DSF; 31 rue Croix des Petits Champs; 75001 Paris France.

${ }^{\S}$ Université Paris Dauphine. Email: mariana.rojas-breu@dauphine.fr; LEDa-SDFi; Place du Maréchal de Lattre de Tassigny- 75775 Paris Cedex 16 France. 


\section{Introduction}

The unification of banking markets is an overlooked issue of monetary union arrangements. In the two prominent examples of monetary unions formed during the last two centuries - the United States and the Euro Area - the original design endowed a single organization with the right to issue currency, while regulation and supervision of banks remained in the state domain 1 B Both ended up by devolving part of banking regulation and supervision to the federal authorities ${ }^{2}$ This paper shows that this did not occur by chance. Instead we argue that credit market integration is a requisite to reap the gains of a unique currency.

A single currency is defined by common rules governing the issuance of the currency-i.e., cash and balances held at the central bank - and equal access to cash for any resident of the zone. The degree of credit market integration between countries depends on banks' decisions, given the technological, legal and regulatory costs of granting cross-border credit. Consequently, one can have perfect integration with respect to the currency dimension - no cost for agents to pay with currency-but imperfect integration of credit markets ${ }^{3}$ In this paper, we define imperfect credit market integration as a situation in which residents of a country pay a cross-border credit premium when financing purchases in another country of the currency zone. We show why this premium may threaten the welfare gains of a unique currency.

The underlying mechanism is as follows. In an environment with imperfect credit market integration, the increase in transactions associated with a single currency may worsen default incentives on bank loans. Given the positive cross-border credit premium, banks charge a higher interest rate for cross-border purchases than

\footnotetext{
${ }^{1}$ The U.S. constitution is the founding act of the currency union in the United States. The U.S. regime of banknote issuance varied during the 19th century but the Mint was always the authority in charge of issuing the dollar in specie, see Rolnick, Smith, and Weber (2003). The Maastricht treaty creates the euro and endows the European Central Bank with the right to issue the currency.

${ }^{2}$ In the Euro Area the negotiations on policies aimed at deepening credit market integration were grouped under the heading "banking union". They encompass the devolution of banking supervision from state supervisors to the ECB and an agreement on common rules and funding for bank resolution, see inter alia Beck (2012), Nieto and White (2013).

${ }^{3}$ The U.S. experience exemplifies the distinction between a currency union and a fully-fledged monetary union. During the 19th century periodic systemic banking crises triggered discussions on the redesign of the regime of currency issuance (Rousseau, 2013). For example White (1982) argues that during the National Banking Act period differences in regulatory frameworks caused distortions on the credit market that "stimulated the public to press for currency and banking reform". This political pressure for currency reform was popularized by the novel of the Wizard of Oz, see Rockoff (1990). The exact moment at which the U.S. banking market became unified is still debated (Rockoff, 2003). The consensus is that the integration in terms of payment instruments (James and Weiman, 2010) and interbank funding (Davis, 1965, Sylla, 1969, James, 1976) started at the beginning of the 20th century. The integration was reinforced by the creation of the FED (Miron, 1986). Since then it is commonplace to pay in Boston with checks drawn for example on Chicago.
} 
for domestic purchases. This creates a wedge between the cost of foreign versus domestic purchases, which induces borrowers - agents with no record of defaultto be biased towards domestic goods instead of making their decisions solely based on preferences. An endogenous home bias results. By contrast an agent that would default and lose access to credit-something that does not happen on the equilibrium path - would not be impacted by the cross-border credit premium anymore, and would thereby be induced to purchase goods in line with his preferences. Therefore, an imposition of conversion costs between currencies can make default less attractive, as this cost affects defaulters more severely than non-defaulters, thereby relaxing borrowing constraints. By contrast, when financing conditions are the same for domestic and cross-border purchases, there is no home bias, and a conversion cost between currencies does not attenuate default incentives. Thus under sufficiently high credit integration welfare is always higher with a unique currency.

We build a symmetric two-country model of fiat money and credit. Currency (fiat money) and bank credit are used in equilibrium by residents of each country to purchase domestic or foreign goods. In each period, agents are subject to individual consumption and production shocks that cannot be efficiently insured by their cash holdings. As in Berentsen, Camera, and Waller (2007), banks provide insurance against those shocks. Agents with no current need for cash (producers) can deposit their currency holdings at their bank rather than keeping them as idle balances, while those with a current need for cash (buyers) can obtain credit from banks to finance additional purchases 4 By lending out the cash received in deposits, banks effectively redistribute the money stock according to agents' current transaction needs. Banks help to finance purchases of domestic and foreign goods, but at a higher price for cross-border purchases. Because agents cannot commit to repay their debt, banks resort to borrowing constraints and to the exclusion of defaulters from future access to their services in order to ensure debt repayment.

To evaluate the gains generated by a currency union in this environment, we compare two monetary arrangements: a single currency regime, and a 'one countryone currency' regime with positive conversion costs between the two currencies. The difference between the two regimes lies in the conversion costs, and we ask whether the case with strictly positive conversion costs is dominated in terms of welfare by a currency union-which is equivalent to costless conversion.

Our mechanism delivers two types of results. First, we show that with perfect credit market integration, a unique currency is always the optimal arrangement. When credit market integration is imperfect, a unique currency is optimal if the borrowing constraint is not binding. This occurs when agents are patient enough and inflation is sufficiently high. Conversely, a regime of separate currencies with

\footnotetext{
${ }^{4}$ Given our emphasis on credit markets integration, an important aspect of banks in our setup is that they extend loans in addition to taking deposits. See Bencivenga and Camera (2011) for a model of money and banks where banks provide liquidity insurance on the liability side but cannot extend credit.
} 
positive conversion costs may be preferred when credit market integration is sufficiently low and the borrowing constraint is binding, which occurs if agents are impatient and inflation is sufficiently low. The reason is that in this case the volume of credit is higher in a regime of separate currencies than in a currency union. Second, with binding borrowing constraints, the volume of credit is monotonically decreasing with the cross-border credit premium. Credit crunches - defined as a reduction in the quantity of credit caused by a substantial increase of the cross-border credit premium - are sharper in a currency union with imperfectly integrated credit markets than in a regime of separate currencies.

This paper contributes to the macroeconomic literature on the benefits and costs of monetary unions by showing that their sustainability requires sufficiently integrated credit markets. Otherwise, a currency union may be dominated in terms of welfare. In addition, we contribute to the literature on monetary theory by suggesting a new rationale for the optimality of multiple currencies vis-à-vis a unique currency. In our setup, a regime of separate currencies mitigates the incentive to default on credit and, hence, may be preferred even though it entails higher transaction costs in cross-border trades.

The rest of the paper is organized as follows. The environment is laid out in section 2. The conditions for the existence of (symmetric) equilibria are presented in section 3. Section 4 presents the main results pertaining to the welfare implications of a regime of unique versus multiple currencies when credit market integration varies. Section 5 illustrates the results with the varying credit market integration in the Euro Area since its inception. Section 6 discusses our contribution to the literature. Section 7 concludes. Proofs are relegated to the Appendix.

\section{Environment}

Our model is based on the one-country setup developed by Lagos and Wright (2005), Rocheteau and Wright (2005) and Berentsen, Camera, and Waller (2007). Time is discrete and continues forever. There are two identical countries, the home country and the foreign country, each populated by a continuum of infinitely-lived agents of unit mass. There are two perfectly divisible non-storable country-specific goods: a home good, denoted as $q_{h}$, and a foreign good, denoted as $q_{f}$. Agents discount across periods with factor $\beta$. A period is divided in two subperiods. In each period, two competitive markets open sequentially in each country. Before the first market opens, agents receive an idiosyncratic shock that determines whether they are sellers for the current period and gain no utility from consumption (with probability $(1-b)$ ), or buyers in which case they want to consume, but cannot produce (with probability $b$ ). In the second market, all agents can produce and consume a quantity of a generic good denoted as $x$, and utility from consumption (or disutility from working) is linear in the quantity of good. 
Buyers' preferences in the first subperiod are

$$
\max \left[u\left(q_{f}\right)+\eta q_{f}, u\left(q_{h}\right)\right]
$$

where $\eta$ is a preference shock which can take values $\eta=0, \eta_{1}, \eta_{2}$ with probabilities $\pi_{0}, \pi_{1}$ and $\pi_{2}$, and $0<\eta_{1}<\eta_{2} .^{5}$ The function $u$ satisfies $u^{\prime}(q),-u^{\prime \prime}(q)>0$, $u^{\prime}(0)=\infty$ and $u^{\prime}(\infty)=0$. In addition we assume that $-u^{\prime \prime}(q) q \leq u^{\prime}(q)$. Preferences in (1) are such that in equilibrium buyers will consume the home good in periods in which their preference shock $\eta$ is low and consume the foreign good in periods in which $\eta$ is high. In the former case they trade in the first market of the home country. In the latter case they travel costlessly to trade in the foreign country and come back to the home country to participate in the second market. For sellers, producing a quantity $q_{j}$ (with $j=h, f$ ) in the first subperiod represents a disutility equal to $c\left(q_{j}\right)=q_{j}$.

There are two storable, perfectly divisible and intrinsically useless currencies, the home currency and the foreign currency. For simplicity, the quantity of each currency at the beginning of period $t$ is denoted as $M$. The money supply in each country grows at the gross rate $\gamma=M_{+1} / M$ where the subscript +1 indicates the following period. Agents receive monetary lump-sum transfers from the central bank equal to $T=(\gamma-1) M_{-1}$ during the second market in period $t$. In analogy to the current Euro Area situation, we assume that the central bank has no power to tax agents, such that $\gamma \geq 1.6$ In order to motivate a role for a medium of exchange, traders are assumed to be anonymous so that sellers require immediate compensation when they produce. This assumption rules out bilateral credit but not banking credit.

Currencies can be exchanged before the first market opens. Exchanging currencies represents a disutility cost $\varepsilon$ proportional to the real amount of money exchanged. Given that the money growth rate is assumed to be the same for the two countries, the case in which the $\operatorname{cost} \varepsilon$ is equal to zero is equivalent to a currency union.7

In each country there are competitive banks which take deposits and use them to grant loans. Banking activities take place before the first market opens. De-

\footnotetext{
${ }^{5}$ We assume three realizations of the preference shock $\eta$ to allow for domestic and foreign consumption on the equilibrium path while creating a wedge between the consumption patterns of agents who borrow and those who do not.

${ }^{6}$ This restriction implies that the Friedman rule is not a feasible policy, so that it is optimal for agents to insure against idiosyncratic shocks using both (costly) cash holdings and banks. This assumption could be relaxed, for instance by assuming that the government can use lump-sum taxes but that agents can evade taxation by not participating in the market - see $\mathrm{Hu}$, Kennan, and Wallace (2009) and Andolfatto (2010).

'We focus on the case in which agents only hold the currency of their country of residence. This is for simplicity and could be justified by assuming that agents face an extra cost (e.g. an accounting cost) when holding a mixed portfolio. Since the mechanism presented in the paper does not hinge on this assumption, we make this modeling choice in order to keep the model tractable. Geromichalos and Simonovska (2014) and Zhang (2014) model the choice of an asset portfolio.
} 
posits are taken by banks and paid back during the second subperiod with the corresponding interest. A loan is a bilateral contract between an agent and an individual bank. The loan and the interest are paid back during the second market. Hence credit is intra-period, so that loans and deposits are not rolled over 8

Banks have no enforcement power. However they possess a technology to keep track of agents' financial histories. This implies that they can recognize agents who have defaulted in the past and are thus able to exclude them from banking activities - loans and deposits - for the rest of their lifetimes. For simplicity, we assume that defaulters are excluded from monetary transfers.

Agents contract with banks located in their country of residence since banks can only identify residents (the cost for a bank to identify a non-resident is infinite). Home (foreign) country sellers deposit in the home (foreign) country. Home (foreign) buyers borrow from home (foreign) banks. Agents can contact a bank located in their country regardless of the first market in which they trade. Consistently with Euro Area evidence (Beck, 2012), we assume that a bank bears a management (regulatory) cost $c \geq 0$ when it services a client who pays his purchases abroad. In the model, since banks are competitive and make zero profit in equilibrium, this cost is shifted to borrowers 9 We refer to this cost as the cross-border credit premium. The premium $c$ is modeled as a disutility cost that each borrower incurs when he takes out a loan for foreign consumption. When $c=0$, taking out a loan for foreign or home consumption is equivalent; i.e. credit market integration is perfect. When $c>0$, financing foreign consumption is more costly than financing domestic consumption; i.e., there is imperfect credit market integration.

The sequence of trades within a period is depicted in figure 1 .

\section{Symmetric equilibrium}

We focus on stationary equilibria in which end-of-period real money balances are constant and positive, so that

$$
\gamma=M / M_{-1}=\phi_{-1} / \phi
$$

where $\phi$ is the price of money in real terms during the second market. Let $V(m)$ denote the value function of an agent who holds an amount $m$ of money at the be-

\footnotetext{
${ }^{8}$ As pointed out by Berentsen et al. (2007) quasi-linear preferences in the second market imply that one-period debt contracts are optimal.

${ }^{9}$ In the Euro Area, banks have information on whether transactions are carried out in another jurisdiction, except for those of small amount. They incur costs when dealing with interjurisdictional transactions, and these costs are shifted to customers. For example, clearing checks payable in another jurisdiction is costly. If a buyer wants to pay a transaction of a significant amount with credit, he has to sign a specific contract at a higher interest rate, if a bank should agree to lend. Even though a European Union directive forbids banks to price-discriminate payment services (e.g. ATM withdrawals) by location, withdrawals using credit cards are limited to a couple of thousand euros for premium cards. Moreover customers travelling within the Euro Area with more than 10,000 euros are compelled to submit regulatory declaration to the authorities.
} 


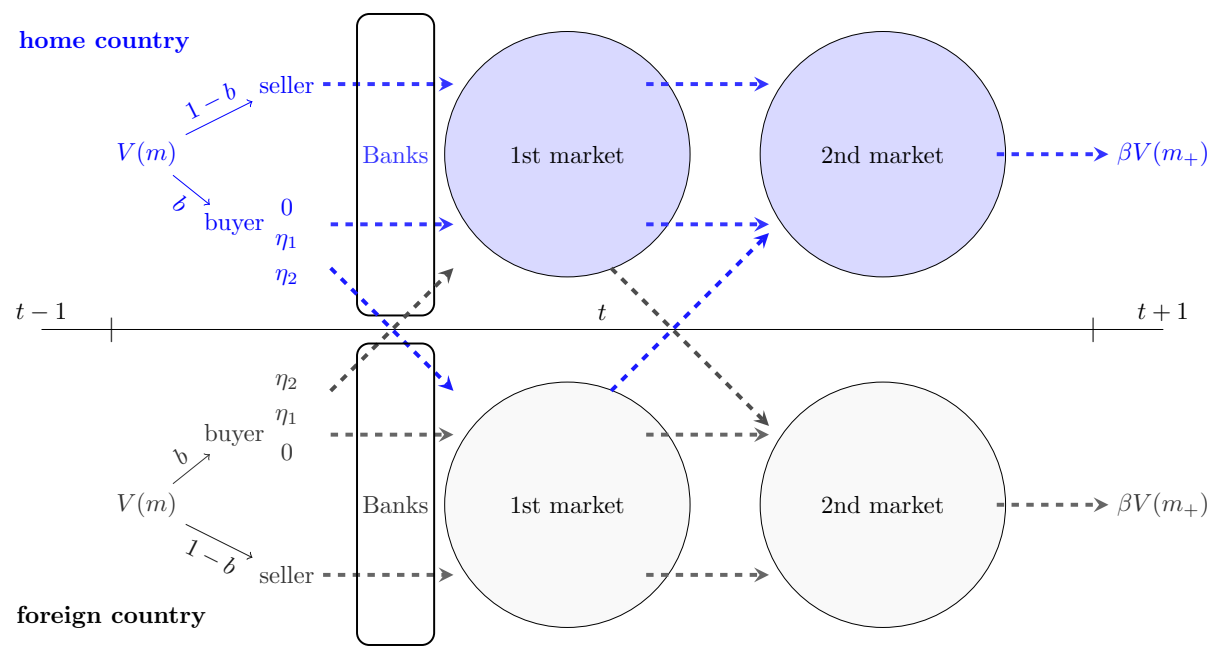

Figure 1: Sequence within a period

ginning of a period, before learning the realization of the preference shock. $W(m, \ell)$ is the expected value from entering the second market with $m$ units of money balances and an amount $\ell$ of loans (a negative amount $\ell$ denotes deposits). In what follows, we analyze a representative period $t$ and solve the model backwards from the second to the first market. Since countries are perfectly symmetric, we only present the optimal choices by agents from the home country.

\subsection{The second market}

In the second market, agents consume or produce, reimburse loans or redeem deposits, and adjust their money balances. Since it is assumed that the crossborder credit premium on foreign loans is paid at the beginning of the period, taking out loans for the consumption of foreign or home goods is equivalent once agents enter the second market; i.e., the interest rate on both type of loans is the same. In addition, since banks are competitive and make zero profit, we already take into account that the interest rate on loans and deposits is the same and denote it by $i$. If an agent has taken out a loan $\ell$, he pays back $\ell(1+i)$ units of money to the bank. If he has deposited an amount $\ell$, he gets it back with the accrued interest, $\ell(1+i)$.

The representative agent chooses his next period monetary holdings, $m_{+1}$, and his consumption (production) of the generic good, $x$, in order to maximize $W(m, \ell)$ subject to the budget constraint:

$$
\begin{gathered}
\max _{x, m_{+1}} W(m, \ell)=x+\beta V\left(m_{+1}\right) \\
\text { s.t. } x+\phi \ell(1+i)+\phi m_{+1}=\phi m+\phi T
\end{gathered}
$$

where $\phi$ is the price of money in terms of the second-market good and $T=$ $(\gamma-1) M_{-1}$ is a lump-sum transfer from the central bank. The budget constraint 
states that the sum of an agent's current consumption, loan repayment (or his deposit's redemption if $\ell<0$ ) and next-period money holdings equals his current money holdings plus the monetary transfer from the central bank.

Inserting the budget constraint in the objective function, the above program simplifies to

$$
\max _{m_{+1}}\left[-\phi m_{+1}+\phi m-\phi \ell(1+i)+\phi T+\beta V\left(m_{+1}\right)\right]
$$

The first-order condition on $m_{+1}$ is

$$
\beta V^{\prime}\left(m_{+1}\right)=\phi
$$

where $V^{\prime}\left(m_{+1}\right)$ is the marginal value of an additional unit of money taken into period $t+1$. Notice that $m_{+1}$ is the same for all agents, regardless of their initial money holdings $m$. The envelope conditions are

$$
\begin{aligned}
W_{m} & =\phi \\
W_{\ell} & =-\phi(1+i)
\end{aligned}
$$

\subsection{The first market}

\subsubsection{Sellers}

Since sellers do not derive utility from consumption, they choose to deposit their currency holdings at the bank instead of borrowing. Let $p$ denote the price of firstmarket goods. In the first market the seller chooses how much to produce $q_{s}$ and the amount of his deposit $-\ell_{s}$. The program for a seller in the first market is

$$
\begin{gathered}
\max _{q_{s}, \ell_{s}}\left[-q_{s}+W\left(m_{-1}+\ell_{s}+p q_{s}, \ell_{s}\right)\right] \\
\text { s.t. }-\ell_{s} \leq m_{-1}
\end{gathered}
$$

where $m_{-1}$ are currency holdings taken from the previous period. The first-order condition on $q_{s}$ is

$$
W_{m} p=1
$$

Using (4), it becomes

$$
\phi p=1
$$

Condition (5) states that sellers are indifferent between producing in the first market and producing in the second market.

The first-order condition on $\ell_{s}$ can be written as

$$
\phi i=\mu_{s}
$$

where $\mu_{s}$ is the multiplier associated with the deposit constraint. According to condition (6), if the interest rate is positive, the deposit constraint is always binding and sellers deposit their entire currency holding at a bank. 


\subsubsection{Buyers}

At the beginning of each period, buyers learn the realized value of the preference shock $\eta$ that increases the utility of consuming the foreign good. Then, buyers decide to consume in their home country or abroad during the first market. Given preferences (1), it is straightforward to see that buyers' travel decisions follow a simple cutoff rule: Any buyer consumes the home good when $\eta \leq \eta^{*}$ and consumes the foreign good when $\eta>\eta^{*}$, where the threshold $\eta^{*}$ is endogenously determined (see Section 3.5).

Denote as $q_{h}^{\eta}\left(q_{f}^{\eta}\right)$ the quantity of home (foreign) goods consumed by a buyer with preference shock $\eta$. Denote as $\ell_{h}^{\eta}\left(\ell_{f}^{\eta}\right)$ the loan taken out by a buyer with preference shock $\eta$ who consumes the home (foreign) good. Since banks can distinguish domestic from foreign transactions, they can potentially set different borrowing limits. Let $\bar{\ell}_{f}$ indicate the maximal amount that an agent traveling abroad can borrow. Similarly $\bar{\ell}_{h}$ indicates the borrowing limit for an agent who consumes the home good.

Since optimal quantities may differ for buyers who stay in the home country and those who travel abroad, we distinguish two cases. Consider first a buyer who consumes the home good (that is with shock $\eta \leq \eta^{*}$ ). This buyer maximizes the utility from consuming $q_{h}^{\eta}$ subject to two constraints:

$$
\begin{gathered}
\max _{q_{h}^{\eta}, \ell_{h}^{\eta}} u\left(q_{h}^{\eta}\right)+W\left(m_{-1}+\ell_{h}^{\eta}-p q_{h}^{\eta}, \ell_{h}^{\eta}\right) \\
\text { s.t. } p q_{h}^{\eta} \leq m_{-1}+\ell_{h}^{\eta} \\
\ell_{h}^{\eta} \leq \bar{\ell}_{h}
\end{gathered}
$$

The first constraint is the cash constraint by which the buyer cannot spend more than his initial money holdings plus his loan. The second constraint is the borrowing constraint set by banks to ensure loan repayment (see Section 3.6).

Using (4) and (5), the first-order condition on $q_{h}^{\eta}$ is

$$
u^{\prime}\left(q_{h}^{\eta}\right)=1+\mu_{h}^{\eta} / \phi
$$

where $\mu_{h}^{\eta}$ is the multiplier associated with the cash constraint (7). The first-order condition on $\ell_{h}^{\eta}$ for this buyer can be written as

$$
\mu_{h}^{\eta}-\phi i=\lambda_{h}^{\eta}
$$

where $\lambda_{h}^{\eta}$ is the multiplier associated with the borrowing constraint (8). Using (9) to substitute for $\mu_{h}^{\eta}$, condition 10 can be rewritten as

$$
u^{\prime}\left(q_{h}^{\eta}\right)=1+i+\lambda_{h}^{\eta} / \phi .
$$

Consider next the program for a buyer who consumes abroad (with shock $\eta>\eta^{*}$ ). 
His consumption quantity solves:

$$
\begin{gathered}
\max _{q_{f}^{\eta}, \ell_{f}^{\eta}} u\left(q_{f}^{\eta}\right)+(\eta-\varepsilon) q_{f}^{\eta}-c \ell_{f}^{\eta} / p+W\left(m_{-1}+\ell_{f}^{\eta}-p q_{f}^{\eta}, \ell_{f}^{\eta}\right) \\
\text { s.t. } p q_{f}^{\eta} \leq m_{-1}+\ell_{f}^{\eta}, \\
\ell_{f}^{\eta} \leq \bar{\ell}_{f}
\end{gathered}
$$

Compared to the buyer who consumes the home good, the buyer who consumes the foreign good incurs conversion costs on his purchase $\left(\varepsilon q_{f}^{\eta}\right)$ and the cross-border credit premium which is proportional to the real amount of the loan taken out $\left(c \ell_{f}^{\eta} / p\right)$.

Using (4) and (5), the first-order condition on $q_{f}^{\eta}$ is

$$
u^{\prime}\left(q_{f}^{\eta}\right)+\eta=1+\varepsilon+\mu_{f}^{\eta} / \phi
$$

where $\mu_{f}^{\eta}$ is the multiplier associated with the cash constraint 12 . The first-order condition on $\ell_{f}^{\eta}$ can be written as

$$
u^{\prime}\left(q_{f}^{\eta}\right)+\eta-\varepsilon-c=1+i+\lambda_{f}^{\eta} / \phi
$$

where $\lambda_{f}^{\eta}$ is the multiplier associated with the borrowing constraint 13 .

\subsection{Market clearing}

Market clearing in the loan market yields

$$
(1-b) \ell_{s}+b \sum_{\eta \leq \eta^{*}} \pi_{\eta} \ell_{h}^{\eta}+b \sum_{\eta>\eta^{*}} \pi_{\eta} \ell_{f}^{\eta}=0
$$

The sum of the deposits made by sellers and the loans taken out by all buyers-i.e., those who consume the home good and those who consume the foreign good - is equal to zero. For sellers, it is optimal to deposit their entire money holdings for any $\gamma \geq 1$. Thus $m_{-1}=-\ell_{s}$, and $(16)$ becomes

$$
(1-b) m_{-1}=b \sum_{\eta \leq \eta^{*}} \pi_{\eta} \ell_{h}^{\eta}+b \sum_{\eta>\eta^{*}} \pi_{\eta} \ell_{f}^{\eta}
$$

Since countries are symmetric, market clearing in the first market for goods yields

$$
b \sum_{\eta \leq \eta^{*}} \pi_{\eta} q_{h}^{\eta}+b \sum_{\eta>\eta^{*}} \pi_{\eta} q_{f}^{\eta}=(1-b) q_{s}
$$




\subsection{Marginal value of money}

The expected utility for an agent who starts a period with $m$ units of money is:

$$
\begin{aligned}
V(m) & =b \sum_{\eta \leq \eta^{*}} \pi_{\eta}\left[u\left(q_{h}^{\eta}\right)+W\left(m+\ell_{h}^{\eta}-p q_{h}^{\eta}, \ell_{h}^{\eta}\right)\right] \\
& +b \sum_{\eta>\eta^{*}} \pi_{\eta}\left[u\left(q_{f}^{\eta}\right)+(\eta-\varepsilon) q_{f}^{\eta}-\phi \ell_{f}^{\eta} c+W\left(m+\ell_{f}^{\eta}-p q_{f}^{\eta}, \ell_{f}^{\eta}\right)\right] \\
& +(1-b)\left[-q_{s}+W\left(m+\ell_{s}+p q_{s}, \ell_{s}\right)\right]
\end{aligned}
$$

Given (5) cash constraints (7) and (12) imply that

$$
\begin{aligned}
& q_{h}^{\eta} \leq \phi\left(m_{-1}+\ell_{h}^{\eta}\right) \\
& q_{f}^{\eta} \leq \phi\left(m_{-1}+\ell_{f}^{\eta}\right)
\end{aligned}
$$

Using (4), (5), (6), (9) and (14), the marginal value of money is

$$
\partial V / \partial m=b \phi \sum_{\eta \leq \eta^{*}} \pi_{\eta} u^{\prime}\left(q_{h}^{\eta}\right)+b \phi \sum_{\eta>\eta^{*}} \pi_{\eta}\left[u^{\prime}\left(q_{f}^{\eta}\right)+\eta-\varepsilon\right]+(1-b) \phi(1+i)
$$

Using (2) and (3), this condition becomes

$$
\gamma / \beta=b \sum_{\eta \leq \eta^{*}} \pi_{\eta} u^{\prime}\left(q_{h}^{\eta}\right)+b \sum_{\eta>\eta^{*}} \pi_{\eta}\left[u^{\prime}\left(q_{f}^{\eta}\right)+\eta-\varepsilon\right]+(1-b)(1+i)
$$

The left-hand side of this equation represents the marginal cost of acquiring an additional unit of money while the right-hand side represents its marginal benefit: With probability $b$ the agent consumes the home good (for $\eta \leq \eta^{*}$ ) or the foreign good (for $\eta>\eta^{*}$ ), and with probability $(1-b)$ the agent is a seller and earns interest on his deposits.

\subsection{Travel decision}

As discussed above, buyers' travel equilibrium decisions can be represented by a threshold $\eta^{*}$ such that buyers with shock $\eta \leq \eta^{*}$ consume at home while buyers with $\eta>\eta^{*}$ consume abroad. This threshold corresponds to the virtual value of the preference parameter $\eta$ such that the value of staying in the home country is equal to the value of traveling to the foreign country. The threshold $\eta^{*}$ is defined by

$$
u\left(q_{h}^{\eta^{*}}\right)-\phi \ell_{h}^{\eta^{*}}(1+i)=u\left(q_{f}^{\eta^{*}}\right)+q_{f}^{\eta^{*}}\left(\eta^{*}-\varepsilon\right)-\phi \ell_{f}^{\eta^{*}}(1+i+c) .
$$

On the left-hand side of (21), the value of purchasing $q_{h}^{\eta^{*}}$ is equal to the utility from consumption minus the cost of reimbursing the loan for home-good consumption. On the right-hand side of 21 , the value of purchasing $q_{f}^{\eta^{*}}$ is equal to the utility from consumption minus the cost of reimbursing the loan for foreign-good consumption and the conversion costs. 


\subsection{Borrowing constraint}

Banks have no enforcement power. Therefore they must set a borrowing constraint that ensures voluntary debt repayment: They choose the amount of loans $\bar{\ell}_{h}$ and $\bar{\ell}_{f}$ such that the payoff to an agent who repays his debt is at least equal to the payoff to a defaulter.

Denote as $\hat{q}_{h}^{\eta}\left(\hat{q}_{f}^{\eta}\right)$ the quantity of the home (foreign) good consumed by an agent with preference shock $\eta$ who has defaulted in the past. The term $\hat{m}_{-1}$ denotes money holdings brought by a defaulter from the previous period.

Since utility from consuming the foreign good is higher than utility from consuming the home good for $\eta>0$ given (1), defaulters could be cash-constrained for $\eta=\eta_{1}, \eta_{2}$ and not cash-constrained for $\eta=0$. Lemma 1 states that defaulters are cash-constrained for all realizations of $\eta$ if $\beta$ is low relative to the additional expected utility from consuming the foreign good as opposed to consuming the home good 10

Lemma 1 Assume $\beta \leq\left[1+b\left(\pi_{1} \eta_{1}+\pi_{2} \eta_{2}\right)\right]^{-1}$. Then defaulters are cash-constrained for all realizations of $\eta$.

Given Lemma 1, we can set $\hat{q}_{h}^{\eta}=\hat{q}_{f}^{\eta}=\hat{q}$ and $\hat{m}_{-1}=p \hat{q}$ for all $\eta$, since defaulters do not have access to the banking system. Let $\hat{\eta}^{*}$ denote the threshold describing the optimal travel decision for an agent who has defaulted in the past. In periods in which $\eta \leq \hat{\eta}^{*}$ the defaulter consumes the home good, whereas in periods in which $\eta>\hat{\eta}^{*}$ the defaulter consumes the foreign good. The threshold $\hat{\eta}^{*}$ is given by

$$
u(\hat{q})=u(\hat{q})+\left(\hat{\eta}^{*}-\varepsilon\right) \hat{q}
$$

According to this condition $\hat{\eta}^{*}$ is determined such that the utility derived from consuming the home good is equal to the utility from consuming the foreign good minus the conversion cost. Hence,

$$
\hat{\eta}^{*}=\varepsilon
$$

Let $\hat{V}(\hat{m})$ indicate the expected utility for a defaulter who starts a period with $\hat{m}$ units of money and $\hat{W}(\hat{m})$ indicate the expected utility for a defaulter with $\hat{m}$ units of money at the beginning of the second market. $\hat{V}(\hat{m})$ is

$$
\begin{aligned}
\hat{V}(\hat{m}) & =b \sum_{\eta \leq \hat{\eta}^{*}} \pi_{\eta}[u(\hat{q})+\hat{W}(0)]+b \sum_{\eta>\hat{\eta}^{*}}[u(\hat{q})+(\eta-\varepsilon) \hat{q}+\hat{W}(0)] \\
& +(1-b)\left(-q_{s}+\hat{W}\left(\hat{m}+p q_{s}\right)\right)
\end{aligned}
$$

where $\hat{q}$ is determined by the optimal condition on the money holdings of the defaulter:

$$
\gamma / \beta=b u^{\prime}(\hat{q})+b \sum_{\eta>\hat{\eta}^{*}} \pi_{\eta}(\eta-\varepsilon)+1-b
$$

\footnotetext{
${ }^{10}$ Notice that in this model, without preference shocks $\left(\pi_{1}, \pi_{2}=0\right)$ and given that $\gamma \geq 1$, the condition in Lemma 1 is simply $\beta \leq 1$.
} 
Lemma 2 An agent who borrows debt $\ell$ has an incentive to repay his debt if, and only if,

$$
-\phi \ell(1+i)-\phi m_{+1}+\phi T+\beta V\left(m_{+1}\right) \geq-\phi \hat{m}_{+1}+\beta \hat{V}\left(\hat{m}_{+1}\right),
$$

Equation (24) can be expressed equivalently as

$$
\begin{aligned}
& -\phi\left[\ell(1+i)+m_{+1}-T\right] \\
& +\frac{\beta b}{1-\beta}\left\{\sum_{\eta \leq \eta^{*}} \pi_{\eta}\left[u\left(q_{h}^{\eta}\right)-q_{h}^{\eta}\right]+\sum_{\eta>\eta^{*}} \pi_{\eta}\left[u\left(q_{f}^{\eta}\right)+(\eta-1-\varepsilon) q_{f}^{\eta}-\phi \ell_{f}^{\eta} c\right]\right\} \\
& \geq \frac{\beta b}{1-\beta}\left[u(\hat{q})-\hat{q}+\sum_{\eta>\hat{\eta}^{*}} \pi_{\eta}(\eta-\varepsilon) \hat{q}\right]-\frac{(\gamma-\beta) \hat{q}}{1-\beta} .
\end{aligned}
$$

Thus banks set identical limits $\bar{\ell}_{h}=\bar{\ell}_{f}=\bar{\ell}$ for home-goods consumption loans and foreign-goods consumption loans.

The left-hand side of the borrowing constraint in equation (25) in Lemma 2 represents the pay-off to an agent who does not default. In period $t$, this agent works to pay his loan with the corresponding interest and to recover his money holdings. From $t+1$ onwards, his expected utility is determined by the net utility he obtains from consuming the foreign good (minus conversion costs and the crossborder credit premium) each time he turns out to be a buyer with $\eta>\eta^{*}$ or by the net utility he obtains from consuming the home good each time he turns out to be a buyer with $\eta \leq \eta^{*}$.

The right-hand side of the borrowing constraint represents the pay-off to a defaulter. If an agent defaults, he does not work to repay the loan taken at the beginning of $t$, nor does he pay the interest on it. His expected lifetime utility is given by the net utility from consuming $\hat{q}$ as a buyer from $t+1$ onwards, minus the cost of adjusting money holdings from $t$ onwards, equal to $(\gamma-\beta) \hat{q} /(1-\beta)$.

Banks set the borrowing limits $\bar{\ell}_{h}$ and $\bar{\ell}_{f}$ at the same value $\bar{\ell}$. The reason is that since the cost $c$ is paid at the moment at which the loan is granted, it does not affect the borrowing constraint.

\subsection{Unconstrained and fully-constrained equilibria}

The following propositions provide conditions on parameter values for the existence of an equilibrium in which agents are not credit constrained (Proposition 1) and for the existence of a fully constrained equilibrium in which all agents are credit constrained (Proposition 2).

Definition 1 An equilibrium is a vector of consumption quantities $\left\{q_{h}^{\eta}, q_{f}^{\eta}, \hat{q}\right\}$, traveling thresholds $\left\{\eta^{*}, \hat{\eta}^{*}\right\}$, interest rate $i$, price of money $\phi$, money holdings 
$m_{-1}$, loans $\left\{\ell_{h}^{\eta}, \ell_{f}^{\eta}\right\}$, borrowing limit $\bar{\ell}$ and multipliers associated with the borrowing constraint $\left\{\lambda_{h}^{\eta}, \lambda_{f}^{\eta}\right\}$ for $\eta \in\left\{0, \eta_{1}, \eta_{2}\right\}$ which satisfy $m_{-1}=M_{-1}, 11$, 15, , 17), (19)-(23) and (25). An equilibrium is unconstrained if the borrowing constraint (25) is slack for all values of $\eta$. An equilibrium is fully constrained if the borrowing constraint (25) binds for all values of $\eta\left(\ell_{h}^{\eta}=\ell_{f}^{\eta}=\bar{\ell}\right.$ for all $\left.\eta\right)$.

Proposition 1 If $\beta$ is sufficiently high there is $\tilde{\gamma}$ such that if $\gamma \geq \tilde{\gamma} \geq 1$, a unique unconstrained equilibrium exists.

Proposition 1 states that if the rate of money growth $\gamma$ is high enough, then an unconstrained equilibrium exists and this equilibrium is unique. For all realizations of $\eta$, agents are able to borrow as much as they desire at the prevailing interest rate. This result is usual in monetary models with limited commitment, and it extends the result of Proposition 4 in Berentsen et alii (2007) to a two-country framework with (potentially imperfect) credit market integration 11

This result comes from the impact of inflation on consumption and thus on expected utility. Agents choose the consumption quantity bought in the first market by equating the marginal utility of consumption in this market to the marginal cost of carrying money from the second market in $t$ to the first market in $t+1$. If the rate of money growth $\gamma$ is higher than the discount factor $\beta$, carrying money throughout periods is costly, because agents need to acquire their money holdings before purchasing goods. The higher $\gamma$ is, the higher the cost of carrying money is, and therefore the higher the marginal utility of consumption in the first marketor the lower the level of consumption. The cost of carrying money is mitigated for non-defaulters by the fact that they earn interest on their idle cash balances when they turn out to be sellers. Therefore, the mere existence of banks allows agents with access to the banking system to enjoy a higher level of consumption in the first market. On the contrary, defaulters are unable to deposit their cash balances and hence do not earn any interest on them. Consequently, they bear a higher cost of carrying money and enjoy a lower level of consumption. When inflation rises to a certain point, defaulters' consumption will be so low that agents are unwilling to default. Thus the borrowing constraint is not binding. As a result, there is a level of inflation above which agents borrow their desired amount of money at equilibrium interest rates.

Proposition 2 If $\beta, \eta_{1}$ and $\eta_{2}$ are sufficiently low, there is $\left\{\gamma^{1}, \gamma^{2}\right\}$ with $1 \leq$ $\gamma^{1}<\gamma^{2}<\tilde{\gamma}$ such that if $\gamma \in\left[\gamma^{1}, \gamma^{2}\right]$ a fully constrained equilibrium exists. In this fully constrained equilibrium the threshold $\eta^{*}$ satisfies

$$
\eta^{*}=\varepsilon+(1-b) c
$$

If $\eta_{1}>\eta^{*}$, buyers consume the home good with probability $\pi_{0}$. If $\eta^{*} \geq \eta_{1}>\varepsilon$ buyers consume the home good with probability $\left(\pi_{0}+\pi_{1}\right)$.

\footnotetext{
${ }^{11}$ See also Aiyagari and Williamson 2000), Corbae and Ritter (2004).
} 
In a fully constrained equilibrium, all buyers would like to borrow more money than the banks are willing to provide at the prevailing equilibrium interest rate. Proposition 2 states that a fully constrained equilibrium exists when the inflation rate is positive and low enough, provided that the discount factor $\beta$ and the values of the preference shock $\eta_{1}$ and $\eta_{2}$ are low enough.12 When inflation is low, the marginal cost of carrying money is low, and defaulters obtain a relatively high level of consumption. Incentives to default are high and the borrowing constraint is binding: Only a limited amount of credit can be sustained in equilibrium because the threat of being excluded from the banking system imposes too mild a cost of default.

Next, we discuss how the travel decision defined in equation (21) is determined in this equilibrium. In the model agents are fully constrained when they are creditconstrained for all realizations of the preference shock $\eta$. In this case, they borrow the same amount of credit and consume the same quantity of goods at home and abroad. Equation (21) can be reduced to equation (26): The threshold $\eta^{*}$ defined by the right-hand side of (26) depends only on the extra cost of purchasing the foreign goods which consists of the conversion cost and the cross-border credit premium. The conversion cost is paid on the total amount purchased whereas the cross-border credit premium $c$ is paid only on the share of consumption financed with a bank loan, equal to $(1-b) 13$

To decide on the country in which he wishes to trade in the first market, the buyer compares the utility derived from the consumption of the foreign good, that depends on the realization of $\eta$ and the extra cost of financing it, with the utility derived from the consumption of the home good. Given the realized preference shock, there is a level of the financing cost above which an agent switches from consumption of the foreign good to consumption of the home good even for a positive value of $\eta$. As stated in Proposition 2, if $\eta_{1}>\varepsilon+(1-b) c$, the crossborder credit premium is low, so buyers consume the home good only when $\eta$ is zero - with probability $\pi_{0}$ - and there is no home-bias. If $\eta_{2}>\varepsilon+(1-b) c \geq \eta_{1}>\varepsilon$ the cross-border credit premium is high and buyers consume the home good when $\eta$ is equal to zero or to $\eta_{1}$-i.e., with probability $\left(\pi_{0}+\pi_{1}\right)$. This defines a home bias in consumption which is triggered by a sufficiently high cross-border credit premium and (or) conversion cost. When the cost of converting one currency into the other is negligible, an agent's bias towards home consumption will be due to imperfect credit market integration.

\footnotetext{
${ }^{12}$ In the main text we do not present the case in which $c$ is so high that buyers never consume the foreign good. The Appendix presents this case with the corresponding proofs.

${ }^{13}$ In this equilibrium the share of consumption financed with credit $l / p q$ is equal to $(1-b)$ whereas the share of consumption financed with cash holdings is $b$, see equation 42 in the proof of Proposition 2 in the Appendix. Intuitively, cash holdings depend positively on the probability $b$ of becoming a buyer since agents are more inclined to accumulate costly money holdings when they have a greater opportunity to spend them. Credit is used to finance the difference between desired consumption and cash holdings.
} 


\section{Currency conversion costs, credit and welfare}

This section presents the main results of the paper. We analyze the effect of making currency exchange costly on both credit and welfare; i.e., on the expected lifetime utility of the representative agent. Given (1), (5) and (18), welfare is defined as

$$
\mathcal{W}=\frac{b}{1-\beta}\left\{\sum_{\eta \leq \eta^{*}} \pi_{\eta}\left[u\left(q_{h}^{\eta}\right)-q_{h}^{\eta}\right]+\sum_{\eta>\eta^{*}} \pi_{\eta}\left[u\left(q_{f}^{\eta}\right)+(\eta-1-\varepsilon) q_{f}^{\eta}-\phi \ell_{f}^{\eta} c\right]\right\}
$$

We ask when a monetary union is optimal; i.e., for which values of the parameter space welfare is maximal when $\varepsilon=0$. We derive conditions on $c$ and $\gamma$ such that agents prefer a regime of separate currencies $(\varepsilon>0)$ instead of a unified currency 14 We then provide a comparative statics result on how credit and welfare depend on $c$. Finally, we construct an example in which a regime of separate currencies is optimal, even if inflation is optimally chosen.

\subsection{When is a monetary union optimal?}

In this section, we show that in economies with money and credit agents prefer a monetary union if, for exogenous reasons, the inflation rate $\gamma$ is high enough or if the credit market integration between countries is deep enough; i.e., the level of cross-border credit premium $c$ is low enough. The next proposition assesses the effect of implementing conversion costs between the two currencies when agents are not credit-constrained.

Proposition 3 In an unconstrained equilibrium, imposing a conversion cost $\varepsilon>0$ leaves the consumption of the home good $\left(q_{h}^{\eta}\right)$ unchanged, decreases the consumption of the foreign $\operatorname{good}\left(q_{f}^{\eta}\right)$ for all $\eta$, increases the real quantity of credit financing home-good consumption $\left(\phi \ell_{h}^{\eta}\right)$ and decreases the real quantity of credit financing foreign good consumption $\left(\phi \ell_{f}^{\eta}\right)$. The overall effect is welfare worsening.

Proposition 3 states that imposing positive conversion costs is unambiguously detrimental to welfare if agents are not borrowing constrained. There are redistributive effects across types - home or foreign - of consumption. Because a positive conversion cost increases the marginal cost of purchasing goods, buyers decrease their expected consumption so that the marginal utility from consumption matches its marginal cost. Conversion cost decreases the equilibrium quantity consumed abroad but leaves the quantity consumed domestically unchanged. Consequently, agents choose to carry a lower amount of costly monetary holdings from one period to the next, as they are anyway able to borrow as much as they want. It

\footnotetext{
${ }^{14}$ We focus on the comparison of steady state welfare levels and abstract from any cost of entry or of exit from a currency union. This comparison can be extended to a setup in which the cost of exit is fixed, as suggested by the empirical discussion in Eichengreen (2007).
} 
follows that agents who stay in the home country choose to increase their borrowing to finance their consumption with each increase in conversion costs. Conversely, agents consuming abroad need to borrow less because the decrease in money holdings is lower than the decrease of their desired foreign consumption. Since the consumption of the foreign good decreases with conversion costs and the consumption of the home good is unaffected, it follows that the overall effect on utility is negative.

Next, we analyze the effect of conversion costs when agents are credit-constrained. The following proposition refers to the case in which agents are credit-constrained and financial integration among countries is sufficiently deep; i.e., $c<\eta_{1} /(1-b)$.

Proposition 4 Let $c<\eta_{1} /(1-b)$. In a fully constrained equilibrium, the imposition of a conversion cost $\varepsilon>0$ triggers a reduction in the consumption of both goods $\left(q_{h}^{\eta}, q_{f}^{\eta}\right)$ and in the real quantity of credit $\left(\phi \ell_{h}^{\eta}, \phi \ell_{f}^{\eta}\right)$ and worsens welfare.

According to Proposition 4 , imposing positive conversion costs is welfare-worsening when agents are credit constrained and the financial markets of the two countries are relatively well integrated; i.e., when the cross-border credit premium $c$ multiplied by the share $(1-b)$ of consumption financed using credit is smaller than the preference $\eta_{1}$ for the foreign good. In the fully constrained equilibrium, agents are constrained for all realizations of $\eta$. Thus, they borrow the same amount, equal to the borrowing limit, regardless of the value of their preference shock. In addition agents reduce their money holdings when conversion costs increase, since the marginal value of money decreases with conversion costs, see equation (20). As a result, an increase in conversion costs entails a reduction in the consumption of both the home good and the foreign good. As in the case in which agents are not constrained, when agents are credit-constrained and financial integration is deep enough, the imposition of conversion costs makes agents reduce their consumption and so it is unambiguously detrimental to welfare.

We can conclude that a monetary union is always optimal when no agent is credit constrained and when all agents are credit-constrained and the cross-border credit premium is low.

\subsection{Monetary and non-monetary causes for monetary disunion}

In this section we explain why the previous result on the optimality of a monetary union may be reversed. We depart from existing models that study the conditions for the optimality of monetary union by explicitly considering the possibility of imperfect credit market integration among countries; i.e., when the premium on granting cross-border credit $c$ is high. We start from a situation of a monetary union between countries - agents do not pay any currency conversion cost $\varepsilon$ - and imperfect financial market integration. We ask whether agents' welfare may be improved by imposing a positive conversion cost between currencies. 
Proposition 5 Let $c>\eta_{1} /(1-b)$. There are $\hat{\pi}_{2}>0$ and $\hat{\gamma}^{2}$ with $\gamma^{1}<\hat{\gamma}^{2} \leq \gamma^{2}$, such that for $\pi_{2} \leq \hat{\pi}_{2}$ and $\gamma \in\left[\gamma^{1}, \hat{\gamma}^{2}\right]$ in a fully constrained equilibrium the imposition of a conversion cost $\varepsilon>0$ increases the consumption of both goods $\left(q_{h}^{\eta}, q_{f}^{\eta}\right)$ and the quantity of credit $\left(\phi \ell_{h}^{\eta}, \phi \ell_{f}^{\eta}\right)$, and improves welfare.

Proposition 5 states that imposing positive conversion costs is welfare improving if agents are credit-constrained, the cross-border credit premium $c$ is sufficiently high, and the probability $\pi_{2}$ of having a strong preference for the foreign good is sufficiently low. A positive conversion cost has a differential impact on the lifetime utility of a defaulter on loan repayment, compared to a non-defaulter. Defaulters consume more often abroad than non-defaulters and hence pay the conversion cost more frequently. A a positive conversion cost therefore reduces the ex ante incentives to default, which relaxes the borrowing constraint. To understand why defaulters are not home-biased while non-defaulters are, let us compare their respective travel and consumption choices. A high level of $c$ reduces the willingness of a non-defaulter to consume the foreign good. When the cost of using credit to finance purchases abroad $(1-b) c$ is greater than $\eta_{1}$, buyers choose to consume the foreign good only when the realized value of $\eta$ is $\eta_{2}$, and choose to consume the home good when $\eta=0, \eta_{1}$. Consuming abroad then occurs with probability $\pi_{2}$. By contrast, a defaulter cannot borrow and hence his decision $\eta^{*}$ is independent of $c$ (see equation 22). When $\varepsilon=0$, he consumes the foreign good for any $\eta$ higher than 0 (for $\left.\eta=\eta_{1}, \eta_{2}\right)$; i.e., with probability $\left(\pi_{1}+\pi_{2}\right)$.

Since defaulters pay the conversion cost more often than home-biased nondefaulters, a positive conversion cost makes default less attractive. In equilibrium a higher level of credit can be sustained, thereby allowing higher consumption. However, conversion costs increase the marginal cost of purchasing goods for nondefaulters as well. Therefore, for conversion costs to be welfare improving, it must be that the probability $\pi_{2}$ is sufficiently small so that the negative effect of conversion costs on the consumption of foreign goods is more than compensated by the effect of conversion costs on incentives to default. The condition that $\pi_{2}$ is lower than the threshold value $\hat{\pi}_{2}$ in Proposition 5 states that the probability $\pi_{2}$ that non-defaulters pay the conversion cost must be relatively low 15

This effect does not hold when the cross-border credit premium is low and agents are credit-constrained, because the consumption pattern is the same for defaulters and non-defaulters. For $c<\eta_{1}(1-b)$ and $\varepsilon=0$, non-defaulters travel if their preference shock $\eta$ is $\eta_{1}$ or $\eta_{2}$, since (26) implies that $\eta_{1}>\eta^{*}$. As a result, $\eta^{*}, \hat{\eta}^{*} \leq \eta_{1}$; i.e., non-defaulters consume the foreign good and therefore pay the conversion costs as often as defaulters.

\footnotetext{
${ }^{15}$ If $c$ is high enough to lead buyers to consume the home good for all realizations of the preference shock $\eta$, conversion costs are only born by defaulters and hence their unique effect is to relax the borrowing constraint. Therefore an increase in conversion costs unambiguously improves welfare regardless of the probabilities associated with the different values of the preference shock. The Appendix contains the proof of this result.
} 
Next we discuss two potential causes for monetary disunion: first a monetary cause - a variation of the level $\gamma$ of monetary injections - and then a non-monetary cause - an increase in the cross-border credit premium $c$.

Monetary cause for currency disunion. We now ask whether a currency disunion may be optimal following a variation in the growth rate of the money supply and hence in the rate of inflation. Proposition 1 states that agents are unconstrained for sufficiently high values of $\gamma$, in which case they always prefer trading in a monetary union according to Proposition 3, regardless of the level of the cross-border credit premium. Proposition 2 states that agents may be creditconstrained for values of $\gamma$ below a certain threshold $\gamma^{2}$. Propositions 4 and 5 refer to the case in which agents are credit-constrained. They state that if the cross-border credit premium $c$ is low enough, welfare is higher in a regime with no conversion costs between currencies than in a regime with positive conversion costs (Proposition 4), whereas the opposite is true if the cross-border credit premium is sufficiently high (Proposition 5). Therefore comparison of propositions 1 and 3 with propositions 2 and 5 suggests the following interpretation: For any sufficiently high level of the cross-border credit premium, a reduction in the level of monetary injection below $\gamma^{2}$ makes agents switch from a preference for the monetary union to a preference for separate monies. The following corollary sums up this discussion.

Corollary 6 A comparison of Propositions 1 and 3 with Propositions 2 and 4 shows that if $c<\eta_{1} /(1-b)$, the currency union is optimal regardless of the level of $\gamma$. Comparison of Propositions 1 and 3 with Propositions 2 and 5 shows that if $c \geq \eta_{1} /(1-b)$, the level of $\gamma$ matters for the optimality of the currency union. In particular, a decrease in the rate of inflation from a high enough level of inflation $(\gamma>\widetilde{\gamma})$ to low levels $\left(\gamma<\gamma^{2}\right)$ can lead to a shift from a situation in which a currency union is optimal to one in which separate currencies are preferred.

Non-monetary cause for monetary disunion. We now look at a potential non-monetary cause for the sub-optimality of a monetary union. We follow a traditional interpretation of financial crises that sees their origin in an increase in the real cost for banks to grant credit. ${ }^{16}$ In our model, the non-monetary factor is a variation of the real cost $c$ for banks to grant cross-border loans. This interpretation is consistent with recent empirical evidence which has shown that the Japanese and the subprime crises had an asymmetric impact on bank lending to the economy: Foreign banks cut credit more than domestic banks, something that may be interpreted as a differential cost of granting credit.17

Following this view, our model suggests that the sustainability of a monetary union is directly impacted by an increase in the cost of the non monetary factor

\footnotetext{
${ }^{16}$ For example $\overline{\text { Gertler and Kiyotaki }}(2007)$

${ }^{17}$ See Peek and Rosengren (1997), De Haas and van Lelyveld (2010), Popov and Udell (2012).
} 
when the inflation rate is low enough. The next corollary summarizes the effect of an increase in $c$ in a situation of low inflation.

Corollary 7 Comparison of Propositions 4 and 5 shows that for low levels of inflation, an increase in the cross-border credit premium from a low level $(c<$ $\left.\eta_{1} /(1-b)\right)$ to a high level $\left(c>\eta_{1} /(1-b)\right)$ may lead to a shift from a situation in which a currency union is optimal to one in which separate currencies are preferred.

Credit crunch compared across monetary regimes. We define a credit crunch as a decrease of the real amount of credit triggered by an exogenous increase in $c$ that is sufficiently high to induce a home bias in consumption. Before comparing the size of a credit crunch across currency arrangements, Proposition 8 establishes that any increase in the cross-border credit premium $c$ reduces the quantity of credit.

Proposition 8 Let $0<c_{0}<\eta_{1} /(1-b)<c_{1}$. If a fully constrained equilibrium exists for all $c \in\left[c_{0}, c_{1}\right]$, an increase in $c$ from $c_{0}$ to $c \leq c_{1}$ leads to a decrease in the real amount of total credit and worsens welfare.

Proposition 8 shows that an increase in $c$ reduces the amount of credit both when it impacts the travel decision and when it does not. The dashed curve in Figure 2 plots the volume of credit as a function of $c$ in a regime of monetary union in a fully constrained equilibrium, 18 For low levels of $c$, credit is continuously decreasing in $c$. When $c$ reaches the threshold value $\eta_{1} /(1-b)$, credit shrinks sharply - the credit crunch-because it makes agents less inclined to consume abroad: Agents who previously consumed the foreign good with probability $\left(\pi_{1}+\pi_{2}\right)$ now opt for consuming it with probability $\pi_{2}$. For values of $c$ greater than $\eta_{1} /(1-b)$, the effect of $c$ on credit is monotonously negative.

Corollary 9 Let $0<c_{0}<\eta_{1} /(1-b)<c_{1}$. A comparison of Propositions 4 and 5 shows that if $c$ increases from $c_{0}$ to $c_{1}$ there is a range of values of $\gamma$ such that the decrease in credit is greater if $\varepsilon=0$ than if $\varepsilon>0$.

Corollary 9 deals with the case in which the increase in $c$ is sufficiently high to generate a home bias in consumption. Such an increase in $c$ generates a sharper decrease in the quantity of credit in a regime of currency union-when $\varepsilon=0$ than in a regime of separate currencies-i.e. when $\varepsilon>0$. The solid line in Figure 2 represents the evolution of credit in a regime of separate currencies. Comparison with the dashed line shows that a monetary union is the regime that provides the highest volume of credit and consumption when $c<\eta_{1} /(1-b)$. However the credit crunch triggered by an increase in $c$ above the threshold $\eta_{1} /(1-b)$ is less accute in a regime of separate currencies than in a monetary union.

\footnotetext{
${ }^{18}$ Figure 2 is drawn assuming that $u(q)=\left(q^{\alpha}\right) / \alpha$ and parameter values $\alpha=0.2, \beta=0.9$, $b=0.3, \eta_{1}=0.02, \eta_{2}=0.05, \pi_{1}=0.2, \pi_{2}=0.02, \gamma=1.01$ and $\varepsilon=0.001$ for the regime of separate currencies. The software program Mathematica was used to check that the conditions for the existence of the fully constrained equilibrium are satisfied.
} 


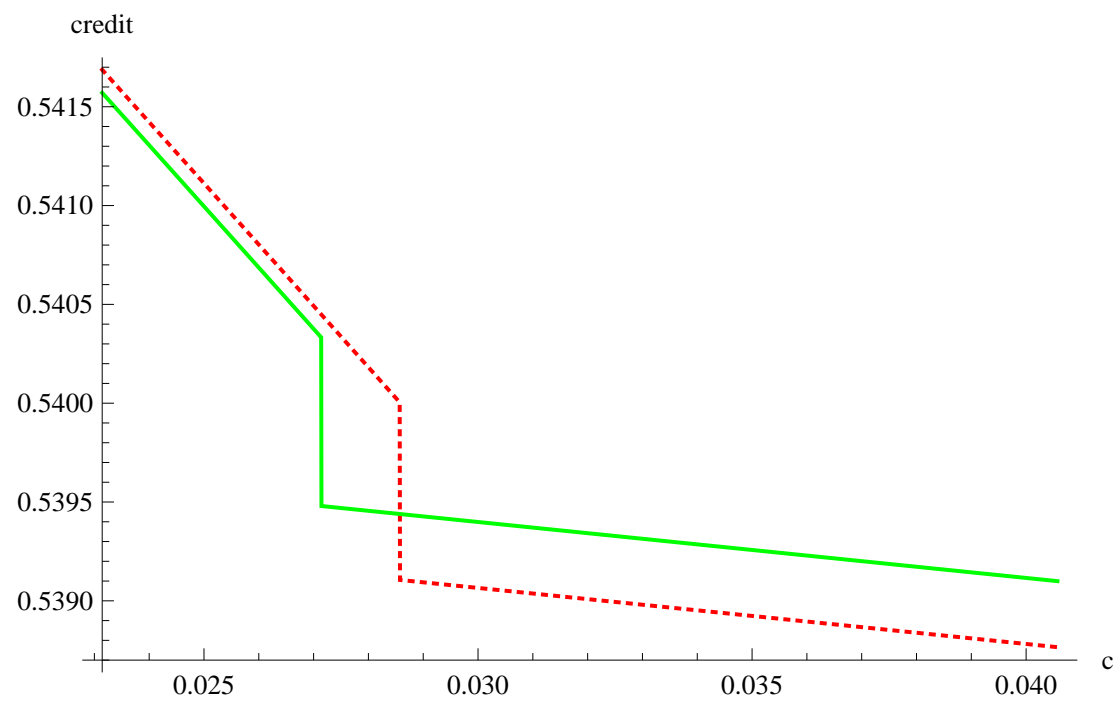

Figure 2: Quantity of credit as a function of the cross-border credit premium $\mathrm{c}$ in a currency union (dashed line) and in a regime of separate currencies (solid line)

\subsection{Conversion cost and optimal inflation}

Proposition 5 shows that under appropriate conditions a strictly positive conversion cost - separate currencies - may relax the borrowing constraint and improve welfare compared to the benchmark case of a currency union. This result is obtained taking the inflation rate $(\gamma)$ as given. However, previous studies of economies with credit and limited commitment show that inflation can be used to curb default incentives ${ }^{19}$ In this section, we present a parametrization in which using positive conversion costs in combination with the inflation rate is necessary to maximize welfare ${ }^{20}$ Given parameter values, in a regime of currency union a fully constrained equilibrium exists up to the threshold value of $\gamma$ equal to $\gamma^{2}=1.021$. The unconstrained equilibrium exists for values of $\gamma$ higher than $\widetilde{\gamma}=1.026$. For intermediate values the equilibrium is partially constrained since agents with preference shocks $\eta_{0}$ and $\eta_{1}$ are credit constrained whereas agents with preference shock $\eta_{2}$ are not.

The simulation reported in Figure 3 shows that parameter values exist for

\footnotetext{
${ }^{19}$ In this type of environment default is a cash-intensive activity. A positive inflation rate thus acts as a tax that discourages default. In the setup we consider, default is a conversion-intensive activity.

${ }^{20}$ Figure 3 is drawn assuming that $u(q)=\left(q^{\alpha}\right) / \alpha$ and parameter values $\alpha=0.2, \beta=0.9$, $b=0.3, c=0.1, \eta_{1}=0.02, \eta_{2}=0.05, \pi_{1}=0.7, \pi_{2}=0.02$ and $\varepsilon=0.015$ for the regime of separate currencies. Notice that in our example $\eta_{1}$ is lower than $(1-b) c$ and that the condition on $\beta$ stated in lemma 1 is verified. The maximum level of welfare is 1.19688 with no conversion costs and 19.691 with positive conversion costs. The software program Mathematica was used to check that the conditions for the existence of the different equilibria are satisfied.
} 


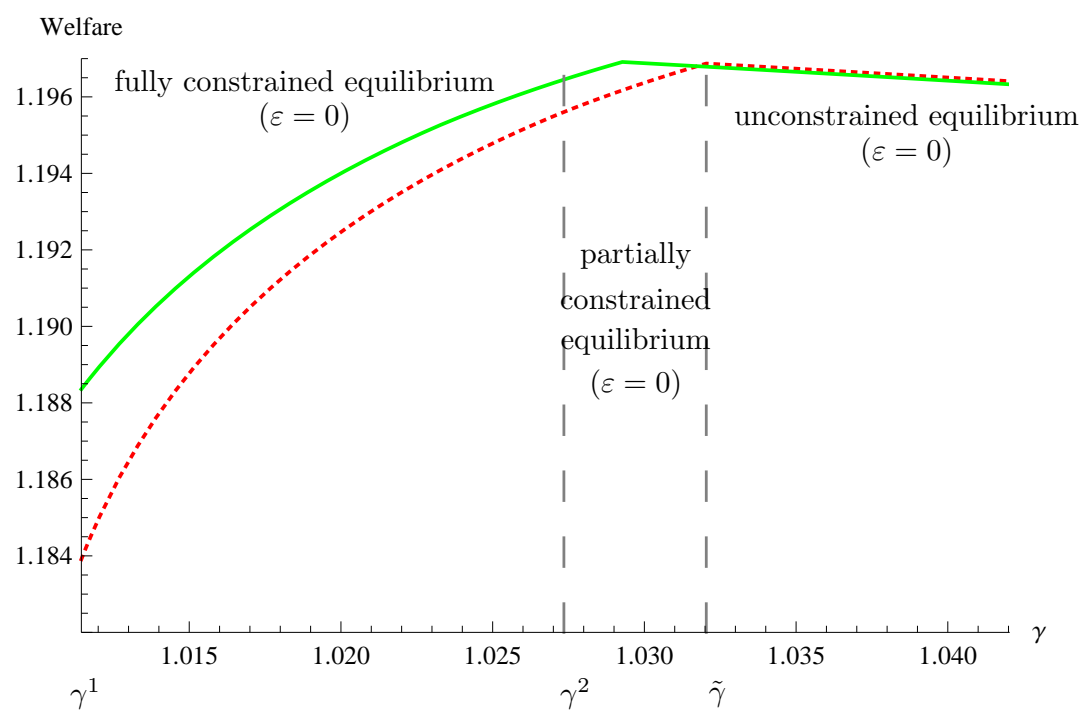

Figure 3: Welfare as a function of inflation in a currency union (dashed line) and in a regime of separate currencies (solid line)

which welfare is higher with positive conversion costs than with an optimal positive rate of inflation in a monetary union. The dashed line corresponds to welfare as a function of the inflation rate when there are no conversion costs. Welfare is maximized at an inflation rate equal to $2.6 \%(\gamma=1.026)$. The solid line represents the welfare attained in a regime of separate currencies. In this example, conversion costs between currencies improve welfare in the fully constrained and partially constrained equilibria even when inflation is chosen optimally. Consistent with Proposition 3, in a unconstrained equilibrium conversion costs worsen welfare.

\section{Empirical illustration with the Euro Area}

We believe that our model is useful for understanding the evolution of credit in the Euro Area. The model predicts that the volume of credit is inversely related to the level of the cross-border credit premium, which is consistent with the observed pattern. As described below, the cross-border credit premium initially decreased in the Euro Area (in particular, owing to initiatives aimed at fostering cross-border financial flows), while credit extended to consumers and firms increased. After the crisis, a reversal in financial market integration occurred, accompanied by an increase in the cross-border credit premium, while a reduction of the volume of credit was observed in crisis-hit countries. In this section, we first review the evolution of financial market integration in the Euro Area. We then discuss the factors that may have specifically influenced the level of the cross border credit premium and its variations over time. 
Variations in financial market integration. Financial market integration in the Euro area increased significantly with the introduction of the euro in 1999 and the various regulatory initiatives aimed at creating a single European financial market (Hartmann, Maddaloni, and Manganelli (2003), ECB (2007), ECB (2012, chapter 2)). The equity, bonds and money markets became quickly integrated (Schoenmaker and Bosch, 2008).

The Subprime and the Euro Crises reversed the trend towards greater financial integration. Milesi-Ferreti and Tille (2011) document a dramatic contraction in cross-border banking activity in the aftermath of the Subprime crisis. The balance sheets of banks exhibited a strong increase in home bias in asset holdings, see Jochem and Volz (2011, using IMF and Bundesbank data) and Acharya and Steffen (2013, using European Banking Authority data). This reversal in banking market integration was also observed in the interbank market. Manna (2011) uses BIS data on the flow of funds between Euro Area and non-Euro Area banking systems to compute a quarterly index of interbank market integration. He documents a Ushaped evolution of the home bias in bank funding for Euro Area countries with the highest integration being reached in 2007 ${ }^{21}$ Importantly this feature is not shared by non-Euro Area countries - United States, United Kingdom, Sweden, Denmark, and Switzerland - where interbank relationships were not durably impacted by the subprime crisis.

Retail credit markets remained mostly fragmented after the creation of the euro (Sørensen and Gutiérrez, 2006, Kleimeier and Sander, 2007). The European Central Bank asserts that "cross-border banking through branches or subsidiaries has remained limited" (ECB, 2012, p.90-91). Foreign banking penetration in each European country - especially the largest ones - is well below the level that prevails in the United States. (Gropp and Kashyap, 2009, Claessens and van Horen, 2012). As ECB President Draghi said "integration [in the Euro area] was largely based on short term interbank debt rather than on equity or direct cross-border lending to firms and households" 22

Variations in the cross-border credit premium. A direct measure of the cross-border credit premium does not exist but anecdotal evidence and indirect measures abound on its technological, legal and institutional components.

The cross-border credit premium is influenced by the higher cost for the interjurisdictional clearing of checks. Jentzsch and San José Rientra (2003) reports that EU banks have less access to cross-border information on their EU customers than U.S. banks have on their customers across U.S. states. The cross-border credit premium is also influenced by differences in the legal and institutional environment, notably concerning the automaticity of judicial cooperation and the differences in debt repayment during the bankruptcy procedures (Djankov, Hart, McLiesh,

\begin{tabular}{l}
\hline${ }^{21}$ This measure is computed as the average over 10 Euro Area countries. \\
\hline${ }^{22}$ In the speech by Mario Draghi, President of the ECB, entitled "A consistent strategy for a \\
\hline sustained recovery", delivered in Paris, 25 March 2014 .
\end{tabular}


and Shleifer, 2008). Bertay, Demirguç-Kunt, and Huizinga (2011) suggest that country-specific financial safety nets act as a barrier to cross-border banking. The level of the cross-border credit premium is also influenced by local idiosyncrasies in regulatory and supervisory frameworks. ${ }^{23}$

The cross-border credit premium has varied over the last fifteen years. The creation of the euro was accompanied by EU initiatives to reduce barriers to the inter-state exchange of financial services. This harmonization must have reduced the cross-border credit premium. Kalemli-Ozcan, Papaioannou, and Peydró (2010) state that the timing of the transposition of the EU financial services directives reflected each state's preference towards cross-border banking integration. Between 1999 and 2014 the supervision of banks remained a state level prerogative. Jentzsch (2007) discusses the discriminatory rules adopted by EU countries to limit competition within their jurisdictions, something that may be interpreted as an increase in the cross-border credit premium. Gros (2012) argues that after 2007 the state supervisors encouraged the fragmentation of local credit markets. The ECB president Mario Draghi related the reversal in credit market integration to the "hidden barriers to cross-border activity linked to national preferences" ${ }^{24}$ This trend towards the ring-fencing of banking activities at the state level is likely to have increased the cross-border credit premium. This trend may have been reversed by the devolution of the supervision of banks to the ECB in November 2014. In this respect, a recently stated objective of the E.C.B. is that "a Spanish firm should be able to borrow from a Spanish bank at the same price at which it would borrow from a Dutch bank" 25

\section{Relation to the literature}

Our work is related to four streams of literature. The paper contributes to the broad macroeconomic literature analyzing the costs and benefits of monetary unions ${ }^{26}$ To underscore our contribution, our stylized framework deliberately leaves aside several dimensions already analyzed in that literature. Our work is also relevant to the literature using monetary search models to assess the effects of multiple currencies.

Asymmetric shocks. We abstract from any source of heterogeneity or asymmetric shocks, so that the type of tradeoffs emphasized in the literature on optimal

\footnotetext{
${ }^{23}$ See Aglietta and Scialom $\sqrt{2003)}$ for a discussion related to the Euro Area supervisory authorities and Houston, Lin, and Ma (2012) for an empirical investigation showing that banks activity is influenced by the regulatory environment.

${ }^{24}$ See Draghi's speech "Financial integration and banking union", delivered in Brussels, 12 February 2014 (p. 5). See also "Banking union and European integration", delivered by ECB Vice-President Constâncio in Vienna, 12 May 2014.

${ }^{25}$ In the speech by Mario Draghi entitled "Europe's pursuit of 'a more perfect union'", delivered in Cambridge (MA), 9 October 2013.

${ }^{26}$ See Mongelli (2002) and Beetsma and Giuliodori 2010) for surveys.
} 
currency areas do not arise in our setup (Mundell, 1961, Benigno, 2004). The main focus of these investigations is on macroeconomic stabilization, and on the cost associated with the loss of the ability to use monetary policy to react to countryspecific shocks. It has been argued that this cost to monetary unification is lower when alternative stabilization tools are available at the national level (Cooper and Kempf, 2004, Gali and Monacelli, 2008) or in the presence of supra-national risksharing arrangements; e.g., through financial integration (Mundell, 1973) or fiscal transfers (Kenen, 1969). By contrast our paper offers a case for credit market integration in a currency union independent of any stabilization or risk-sharing considerations.

Frictions of monetary policy. Several papers have argued that a currency union can mitigate the inflation bias that result from the time inconsistency of monetary policy identified by Barro and Gordon (1983). In Alesina and Barro (2002), countries lacking internal discipline can commit to monetary stability by joining a currency union with a low-inflation anchor country. Cooley and Quadrini (2003) demonstrate that monetary unification allows countries to benefit from lower inflation by internalizing a negative externality arising between independent monetary authorities under no commitment. Such inflation-generating externalities and the resulting gains from monetary policy coordination can stem from individual countries incentives to manipulate terms of trade, or from an attempt to tax the domestic currency holding of foreigners by means of inflation (Cooper and Kempf, 2003, Liu and Shi, 2010). Our work differs from these studies by considering monetary authorities that are fully committed to a given (exogenous) inflation rate. Importantly, we compare the currency union and the separate currencies regimes for the same monetary policy ${ }^{27}$ This allows us to derive new insights into the link between inflation, credit integration and the desirability (or lack thereof) of monetary unions. In particular, we show in Section 4.2 that when credit integration is low a unique currency regime may be optimal only for sufficiently high levels of inflation. This suggests that high-inflation monetary unions are sustainable, and that countries experiencing high inflation may choose to form a monetary union for reasons unrelated to a reduction in the level of the inflation. By contrast, papers analyzing monetary unions as a way to commit to low inflation suggest that one should mainly observe monetary unions with low inflation levels.

Fiscal and monetary policies interactions. Our results are not driven by fiscal considerations and we have no role for public spending and borrowing. This distinguishes our work from the numerous studies that have analyzed the interactions between monetary and fiscal policies in a monetary union. Motivated by the debate on the European Monetary Union, several papers have discussed the

\footnotetext{
${ }^{27}$ However, our results do not hinge on exogenous inflation, and the effect of conversion costs that we identify does not disappear when inflation is chosen optimally (see Section 4.3.
} 
need for fiscal constraints to contain the risk of applying monetary financing of the fiscal deficits to (sub)national governments. Chari and Kehoe (2007) argue that the time-inconsistency problem of the single monetary authority creates a free-rider problem in fiscal policies, leading to excessive debts and inflation in the absence of debt constraints. Beetsma and Uhlig (1999) show that currency integration exacerbates pre-existing moral hazard problems in government borrowing arising from political distortions, thus explaining why countries have incentives to commit to a balance budget after joining a monetary union ${ }^{28}$ These studies focus primarily on the issue of the monetisation of fiscal deficits ${ }^{29}$ ruling out default on government debt. Other papers suggests that the possibility of default on public debt may impact the sustainability of monetary unions. It has been argued that a currency union may be unsustainable because it forbids over-indebted governments to reduce their real debt-burden through inflation and currency devaluation (Goodhart, 2011, De Grauwe, 2013, Sims, 2013). In Aguiar, Amador, Farhi, and Gopinath (2014), the level of welfare and vulnerability to rollover debt crises of countries in a monetary union are shown to depend on the distribution of government debts in the union. These studies focus on default on government debt and are silent about credit market integration. By contrast, we focus on the default incentives of private borrowers and show how credit market integration affects the sustainability of the currency union from the perspective of private agents.

Costs and benefits of multiple currencies. Our work is also related to a few papers analyzing the potential benefits of multiple monies when there is a commitment issue on the side of private agents rather than public authorities. Early search-theoretic models of monetary exchange which investigate the issue of multiple currencies found that one currency is always optimal (see e.g. Matsuyama, Kiyotaki, and Matsui (1993), Wright and Trejos (2001)). Building on Ravikumar and Wallace (2001), Kiyotaki and Moore (2003) show that multiple currencies may be preferred to a single currency when it allows agents to enjoy the benefits of a greater degree of specialization in the production of goods. Kocherlakota and Krueger (1999) provides a setup where multiple monies can be optimal, because they allow agents to credibly signal private information concerning the type of goods (home vs. foreign) that they prefer. In a related vein, Kocherlakota (2002) demonstrates that two monies can be useful by allowing agents to signal their (unobservable) money holdings. We emphasize a distinct tradeoff, making the point that when credit integration is imperfect, a unique currency can increase the

\footnotetext{
${ }^{28}$ One important assumption underlying these results is that the central bank inflates away some of the real value of public debt. In the terminology of Sargent and Wallace (1981), this corresponds to a regime of 'fiscal dominance'. These problems need not arise, and debt constraints may be sub-optimal, in a monetary-dominance regime where the central bank credibly commits to not accommodate fiscal authority's profligacy (Dornbusch, 1997, Chari and Kehoe, 2007).

${ }^{29}$ See Dixit and Lambertini (2001), Trejos (2004) and Cooper, Kempf, and Peled (2010) for related studies. Sargent (2012) uses US history to draw lessons on the coordination of fiscal and monetary policies in a currency union.
} 
outside option associated with default, and exacerbate agents' incentives to default on their bank loans.

\section{Conclusion}

Our paper analyzes whether a currency union is welfare-improving depending on the level of credit market integration. To this end, we construct a two-country model with money and bank credit. The degree of credit market integration is captured by the premium paid by agents to banks to borrow for purchases made in another jurisdiction. We show that when the cross-border credit premium is nil, agents always prefer using a unique currency. However, if countries are unable or unwilling to sufficiently reduce the cross-border credit premium, welfare may be impaired by the adoption of a unique currency. The reason is that a currency union may be a cause of credit rationing when the supply of bank credit adapts to borrowers default incentives. This issue may be especially acute in times of crisis when impediments to cross-border credit increase, thereby increasing the cross-border credit premium.

Since our purpose was to construct the most general model, our analysis remains silent on the specific obstacles to credit market integration. At the state level, one possible obstacle is the limited capacity that banks in individual countries have in seizing collateral or revenue across jurisdictions in the absence of automatic inter-state judicial cooperation. Another possible obstacle is that individual banking supervisory or regulatory authorities may impose limits to cross-border credit. Further potential obstacles are elevated banking charges for cashing-in foreign checks or reduced access to the credit histories of non-residents. We leave the analysis of the welfare impact of these underlying factors on the degree of credit market integration for future research

\section{Appendix}

Proof of Lemma 1. If defaulters are cash-constrained for all realizations of $\eta$, it must be that $u^{\prime}(\hat{q}), u^{\prime}(\hat{q})+\eta_{1}-\varepsilon, u^{\prime}(\hat{q})+\eta_{2}-\varepsilon>1$. Since we only consider

parameter values such that $\eta_{1}, \eta_{2}>\varepsilon$, it is sufficient to show that in the conjectured equilibria $u^{\prime}(\hat{q})>1$ holds. From 22 and $(23)$ we get

$$
u^{\prime}(\hat{q})-1=(\gamma / \beta-1) / b-\left[\pi_{1}\left(\eta_{1}-\varepsilon\right)+\pi_{2}\left(\eta_{2}-\varepsilon\right)\right]
$$

Thus if $\beta \leq\left[1+b\left(\pi_{1} \eta_{1}+\pi_{2} \eta_{2}\right)\right]^{-1}$ it follows that $u^{\prime}(\hat{q})>1$ always holds for $\gamma \geq 1$ and $\varepsilon \geq 0$ so defaulters are cash-constrained for all realizations of $\eta$. 
Proof of Lemma 2. We first show that any agent repays iff (24) holds. First, observe that (24) corresponds to the incentive constraint for any agent at the repayment date (in the second market), and as such must hold for any $\eta$. To show that condition (24) is also sufficient, it suffices to show that no type $\eta$ has an incentive to deviate at the borrowing stage. Let $\Gamma=\beta\left(V\left(m_{+1}\right)-\hat{V}\left(\hat{m}_{+1}\right)\right)-$ $\phi\left(m_{+1}-T-\hat{m}_{+1}\right)$, and rewrite $[24)$ as

$$
\phi \ell(1+i) \leq \Gamma .
$$

This defines a first debt limit $\bar{\ell} \equiv \frac{\Gamma}{\phi(1+i)}$ for all $\eta$. Now, consider an agent with preference shock $\eta$ and debt $\ell^{\eta} \leq \bar{\ell}$ (with $\bar{\ell} \geq 0$ arbitrary). With no loss of generality, consider the case of local consumption. For this agent not to deviate at the borrowing stage, it must be the case that

$u\left(\frac{m+\ell^{\eta}}{p}\right)-\phi \ell^{\eta}(1+i)-\phi m_{+1}+\phi T+\beta V\left(m_{+1}\right) \geq u\left(\frac{m+\bar{\ell}}{p}\right)-\phi \hat{m}_{+1}+\beta \hat{V}\left(\hat{m}_{+1}\right)$,

since an agent that will default borrows up to the limit $\bar{\ell}$. Notice that because the right-hand side is increasing in $\bar{\ell},(30)$ defines a second debt limit $\bar{\ell}^{2}$ to be imposed on type $\eta$. To show that $(30)$ is redundant, we show that $\bar{\ell}^{1} \leq \bar{\ell}^{2}$. Assume the contrary, that is $\bar{\ell}^{1}>\bar{\ell}^{2}$. Using 30 ,

$$
u\left(\frac{m+\bar{\ell}^{2}}{p}\right)=u\left(\frac{m+\ell^{\eta}}{p}\right)-\phi \ell^{\eta}(1+i)+\Gamma,
$$

where $\ell^{\eta}$ is the equilibrium borrowing for type $\eta$. Since $\ell^{\eta}$ is chosen optimally (and $\bar{\ell}^{2}$ can be chosen) we have

$$
u\left(\frac{m+\ell^{\eta}}{p}\right)-\phi \ell^{\eta}(1+i) \geq u\left(\frac{m+\bar{\ell}^{2}}{p}\right)-\phi \bar{\ell}^{2}(1+i) .
$$

From 31 and 32 ,

$$
u\left(\frac{m+\bar{\ell}^{2}}{p}\right) \geq u\left(\frac{m+\bar{\ell}^{2}}{p}\right)-\phi \bar{\ell}^{2}(1+i)+\Gamma,
$$

which gives $\bar{\ell}^{2} \geq \frac{\Gamma}{\phi(1+i)}=\bar{\ell}^{1}$, a contradiction. Hence, $\bar{\ell}^{1} \leq \bar{\ell}^{2}$ and 24 is both sufficient and necessary for repayment incentives.

Since $\bar{\ell}^{1}$ does not depend on $\eta$, it also follows that $\bar{\ell}_{h}=\bar{\ell}_{f}=\bar{\ell}$.

To conclude, we check that $(25)$ is equivalent to 24$)$. Denote as $x_{j}^{\eta}$ and $x_{s}$ the amount of consumption by the buyer with preference shock $\eta$ who consumes good $j=(h, f)$ and the amount of consumption by the seller, respectively, in the second market. When the settlement stage arrives, the pay-off to a buyer with preference 
given by $\eta$ who repays his debt for consumption of good $j=(h, f)$ is:

$$
\begin{aligned}
& x_{j}^{\eta}+\frac{\beta b}{1-\beta}\left\{\sum_{\eta \leq \eta^{*}} \pi_{\eta}\left[u\left(q_{h}^{\eta}\right)+x_{h}^{\eta}\right]+\sum_{\eta>\eta^{*}} \pi_{\eta}\left[u\left(q_{f}^{\eta}\right)+(\eta-\varepsilon) q_{f}^{\eta}-\phi \ell_{f}^{\eta} c+x_{f}^{\eta}\right]\right\} \\
& -\frac{\beta(1-b)}{1-\beta}\left(q_{s}-x_{s}\right)
\end{aligned}
$$

The pay-off to a defaulter with preference shock $\eta$ who consumes good $j=(h, f)$ is

$$
\bar{x}_{j}^{\eta}+\frac{\beta b}{1-\beta}\left\{u(\hat{q})+\sum_{\eta \leq \hat{\eta}^{*}} \pi_{\eta} \hat{x}_{h}^{\eta}+\sum_{\eta>\hat{\eta}^{*}} \pi_{\eta}\left[(\eta-\varepsilon) \hat{q}+\hat{x}_{f}^{\eta}\right]\right\}-\frac{\beta(1-b)}{1-\beta}\left(q_{s}-\hat{x}_{s}\right)
$$

where $\bar{x}_{j}^{\eta}$ is consumption by the agent in the period in which he defaults and $\hat{x}_{h}^{\eta}$, $\hat{x}_{f}^{\eta}$ and $\hat{x}_{s}$ are net consumption by the defaulter in subsequent periods in case he is a buyer with preference shock $\eta \leq \hat{\eta}^{*}$, a buyer with preference shock $\eta>\hat{\eta}^{*}$, or a seller.

Consumption quantities $x_{j}^{\eta}$ and $x_{s}$ are

$$
\begin{aligned}
& x_{j}^{\eta}=-\phi \ell_{j}^{\eta}(1+i)-\phi m_{+1}+\phi T \\
& x_{s}=-\phi \ell_{s}(1+i)+\phi p q_{s}-\phi m_{+1}+\phi T
\end{aligned}
$$

where $T=(\gamma-1) M_{-1}$. In a symmetric equilibrium, $m_{-1}=M_{-1}$. In addition, $m_{-1}=-\ell_{s}$. Using (5), (16)-19) and (33), we verify the market clearing condition in the second market:

$$
b \sum_{\eta \leq \eta^{*}} \pi_{\eta} x_{h}^{\eta}+b \sum_{\eta>\eta^{*}} \pi_{\eta} x_{f}^{\eta}+(1-b) x_{s}=0
$$

Consumption quantities by the defaulter $\bar{x}_{j}^{\eta}, \hat{x}_{h}^{\eta}, \hat{x}_{f}^{\eta}$ and $\hat{x}_{s}$ are

$$
\begin{aligned}
& \bar{x}_{j}^{\eta}=\hat{x}_{h}^{\eta}=\hat{x}_{f}^{\eta}=-\phi \hat{m}_{+1}=-\gamma \hat{q} \\
& \hat{x}_{s}=\hat{x}_{j}^{\eta}+\phi \hat{m}_{-1}+q_{s}=-(\gamma-1) \hat{q}+q_{s}
\end{aligned}
$$

since $\phi \hat{m}_{-1}=\hat{q}$ and $\hat{m}_{+1} / \hat{m}_{-1}=\gamma$. Using (33) and (34), the borrowing constraint can be rewritten as in (25).

Proof of Proposition 1. We first rewrite the equilibrium equations that correspond to an unconstrained equilibrium and then show that the borrowing constraint is effectively slack for $\gamma$ sufficiently high.

Conjecture an unconstrained equilibrium by setting $\lambda_{h}^{\eta}=0$ and $\lambda_{f}^{\eta}=0$ for all $\eta$. From (1), note that the consumption quantity of home goods does not depend on $\eta$ so in what follows we set $q_{h}^{\eta}=q_{h}$ and $\ell_{h}^{\eta}=\ell_{h}$. (11) and (15) become

$$
\begin{aligned}
u^{\prime}\left(q_{h}\right) & =1+i \\
u^{\prime}\left(q_{f}^{\eta}\right)+\eta-\varepsilon-c & =1+i
\end{aligned}
$$


Hence 20 can be rewritten as

$$
\gamma / \beta-b \sum_{\eta>\eta^{*}} \pi_{\eta} c=1+i
$$

Thus, $q_{h}$ and $q_{f}^{\eta}$ are immediately pinned down for a given value of $\gamma$.

From 17) and (19), we get

$$
\phi \ell_{h}=(1-b) q_{h}-b \sum_{\eta>\eta^{*}} \pi_{\eta}\left(q_{f}^{\eta}-q_{h}\right)
$$

and

$$
q_{h}-\phi \ell_{h}=q_{f}^{\eta}-\phi \ell_{f}^{\eta}
$$

for all $\eta$.

From (28), a defaulter effectively consumes $\hat{q}$ for $\gamma$ sufficiently high regardless of the value of the preference shock. From (23), (35), and (36), it follows that $\hat{q}<q_{h}, q_{f}^{\eta}$ for $\gamma$ sufficiently high. Hence, by the mean value theorem $u\left(q_{h}\right)-u(\hat{q})>$ $u^{\prime}\left(q_{h}\right)\left(q_{h}-\hat{q}\right)$. Similarly, $u\left(q_{f}^{\eta}\right)-u(\hat{q})>u^{\prime}\left(q_{f}^{\eta}\right)\left(q_{f}^{\eta}-\hat{q}\right)$. Therefore, a sufficient condition for the borrowing constraint 25) to be non-binding is

$$
\begin{aligned}
& -\phi\left[\ell(1+i)+m_{-1}\right]+\frac{\beta b}{1-\beta}\left\{\sum_{\eta>\eta^{*}} \pi_{\eta}\left[(\eta-\varepsilon) q_{f}^{\eta}-\phi \ell_{f}^{\eta} c\right]-\sum_{\eta>\hat{\eta}^{*}} \pi_{\eta}(\eta-\varepsilon) \hat{q}\right\} \\
& +\frac{\beta b}{1-\beta}\left\{\sum_{\eta \leq \eta^{*}} \pi_{\eta}\left[u^{\prime}\left(q_{h}\right)-1\right]\left(q_{h}-\hat{q}\right)+\sum_{\eta>\eta^{*}} \pi_{\eta}\left[u^{\prime}\left(q_{f}^{\eta}\right)-1\right]\left(q_{f}^{\eta}-\hat{q}\right)\right\} \\
& \geq-\frac{(\gamma-\beta) \hat{q}}{1-\beta}
\end{aligned}
$$

Given (35), (37) and (38), this condition can be rewritten as

$$
\begin{aligned}
& -\phi\left[\ell(1+i)+m_{-1}\right]+\frac{\beta b^{2} c}{1-\beta} \sum_{\eta>\eta^{*}} \pi_{\eta}\left[q_{h}+\sum_{\eta>\eta^{*}} \pi_{\eta}\left(q_{f}^{\eta}-q_{h}\right)\right] \\
& +\frac{\beta b i}{1-\beta}\left(\sum_{\eta \leq \eta^{*}} \pi_{\eta} q_{h}+\sum_{\eta>\eta^{*}} \pi_{\eta} q_{f}^{\eta}\right)+\frac{\beta b}{1-\beta}\left[\sum_{\eta>\eta^{*}} \pi_{\eta}(\eta-\varepsilon)-\sum_{\eta>\hat{\eta}^{*}} \pi_{\eta}(\eta-\varepsilon)\right] \hat{q} \\
& \geq-\frac{(\gamma-\beta) \hat{q}}{1-\beta}+\frac{\beta b}{1-\beta}\left(i+c \sum_{\eta>\eta^{*}} \pi_{\eta}\right) \hat{q}
\end{aligned}
$$

We consider two different cases. First, consider the case of an agent who has consumed the home good in the current period. Using (19), (36) and (37), 39) 
becomes

$$
\begin{aligned}
& -(1-b) q_{h} i+b \sum_{\eta>\eta^{*}} \pi_{\eta}\left(q_{f}^{\eta}-q_{h}\right) i-q_{h}+\frac{\beta b^{2} c}{1-\beta} \sum_{\eta>\eta^{*}} \pi_{\eta}\left[q_{h}+\sum_{\eta>\eta^{*}} \pi_{\eta}\left(q_{f}^{\eta}-q_{h}\right)\right] \\
& +\frac{\beta b i}{1-\beta}\left(\sum_{\eta \leq \eta^{*}} \pi_{\eta} q_{h}+\sum_{\eta>\eta^{*}} \pi_{\eta} q_{f}^{\eta}\right) \\
& \geq-\beta i \frac{1-b}{1-\beta} \hat{q}-\frac{\beta b}{1-\beta}\left[\sum_{\eta>\eta^{*}} \pi_{\eta}(\eta-\varepsilon)-\sum_{\eta>\hat{\eta}^{*}} \pi_{\eta}(\eta-\varepsilon)\right] \hat{q}
\end{aligned}
$$

Since all terms with $q_{f}^{\eta}$ in the above inequality are positive, one way to show that this inequality holds for $\gamma$ sufficiently high is to consider the following sufficient condition

$$
\begin{aligned}
& -q_{h} i-q_{h}+\frac{\beta b^{2} c q_{h}}{1-\beta} \sum_{\eta>\eta^{*}} \pi_{\eta} \sum_{\eta \leq \eta^{*}} \pi_{\eta}+q_{h} i \frac{b}{1-\beta} \sum_{\eta \leq \eta^{*}} \pi_{\eta} \\
& \geq-\frac{\beta i(1-b)}{1-\beta} \hat{q}-\frac{\beta b}{1-\beta}\left[\sum_{\eta>\eta^{*}} \pi_{\eta}(\eta-\varepsilon)-\sum_{\eta>\eta^{*}} \pi_{\eta}(\eta-\varepsilon)\right] \hat{q}
\end{aligned}
$$

Since $\eta^{*} \geq \hat{\eta}^{*}$, note that if $\gamma$ is high enough the right-hand side in the above inequality is unambiguously negative given (36). Therefore, the right-hand side can be dismissed and it is sufficient for this inequality to hold that

$$
\left(-1+\frac{b}{1-\beta} \sum_{\eta \leq \eta^{*}} \pi_{\eta}\right) i \geq 1-\frac{\beta b^{2} c}{1-\beta} \sum_{\eta>\eta^{*}} \pi_{\eta} \sum_{\eta \leq \eta^{*}} \pi_{\eta}
$$

From (36), the left-hand side in the above inequality is increasing in $\gamma$, provided that $\beta$ is sufficiently high (it is sufficient that $\beta>1-b \pi_{0}$ since $\sum_{\eta \leq \eta^{*}} \pi_{\eta} \geq \pi_{0}$ ).

Second, consider the case of an agent who has consumed the foreign good in the current period. Using (19), (36), (37) and (38), (39) can be written as

$$
\begin{aligned}
& \left(-q_{f}^{\eta}+b \sum_{\eta>\eta^{*}} \pi_{\eta} q_{f}^{\eta}+b \sum_{\eta \leq \eta^{*}} \pi_{\eta} q_{h}\right) i-q_{f}^{\eta}+\frac{\beta b^{2} c}{1-\beta} \sum_{\eta>\eta^{*}} \pi_{\eta}\left(\sum_{\eta \leq \eta^{*}} \pi_{\eta} q_{h}+\sum_{\eta>\eta^{*}} \pi_{\eta} q_{f}^{\eta}\right) \\
& +\frac{\beta b i}{1-\beta}\left(\sum_{\eta \leq \eta^{*}} \pi_{\eta} q_{h}+\sum_{\eta>\eta^{*}} \pi_{\eta} q_{f}^{\eta}\right) \\
& \geq-\beta i \frac{1-b}{1-\beta} \hat{q}-\frac{\beta b}{1-\beta}\left[\sum_{\eta>\eta^{*}} \pi_{\eta}(\eta-\varepsilon)-\sum_{\eta>\eta^{*}} \pi_{\eta}(\eta-\varepsilon)\right] \hat{q}
\end{aligned}
$$


In the above inequality, all terms with $q_{h}$ are positive and the right-hand side is negative if $\gamma$ is high enough (as stated in the case of the borrowing constraint for consumption of home goods). Thus, one way to show that this inequality holds for $\gamma$ sufficiently high is to consider the following sufficient condition

$$
\left(-q_{f}^{\eta}+\frac{b}{1-\beta} \sum_{\eta>\eta^{*}} \pi_{\eta} q_{f}^{\eta}\right) i-q_{f}^{\eta}+\frac{\beta b^{2} c}{1-\beta} \sum_{\eta>\eta^{*}} \pi_{\eta} \sum_{\eta>\eta^{*}} \pi_{\eta} q_{f}^{\eta} \geq 0
$$

Since in an equilibrium with positive consumption of foreign goods $q_{f}^{\eta} \leq q_{f}^{\eta_{2}}$ and $\sum_{\eta>\eta^{*}} \pi_{\eta} q_{f}^{\eta} \geq \pi_{2} q_{f}^{\eta_{2}}$, it is sufficient that

$$
\left(-q_{f}^{\eta_{2}}+\frac{b}{1-\beta} \pi_{2} q_{f}^{\eta_{2}}\right) i-q_{f}^{\eta_{2}}+\frac{\beta b^{2} c \pi_{2} q_{f}^{\eta_{2}}}{1-\beta} \sum_{\eta>\eta^{*}} \pi_{\eta} \geq 0
$$

If $\beta>1-b \pi_{2}$, then a sufficient condition is

$$
\left(-1+\frac{b \pi_{2}}{1-\beta}\right) i \geq 1-\frac{\beta b^{2} c \pi_{2}}{1-\beta} \sum_{\eta>\eta^{*}} \pi_{\eta}
$$

From (36), the left-hand side in the above inequality is increasing in $\gamma$, provided that $\beta$ is sufficiently high.

To sum up, 40) and (41) hold if $\gamma$ is sufficiently high. In addition from (36) a high value of $\gamma$ ensures $i \geq 0$. Hence an unconstrained equilibrium exists. Since (36) pins down a unique value of $i$ and 35 pins down unique values of $q_{h}$ and $q_{f}^{\eta}$ for all $\eta$ this equilibrium is unique.

Proof of Proposition 2, First, we derive the threshold $\eta^{*}$ in a conjectured fully constrained equilibrium. In this equilibrium all buyers are credit-constrained. Since the multiplier associated to the borrowing constraint is positive for all realizations of $\eta$, it follows from (10), (14) and (15) that the multiplier associated to the cash constraint is also positive for all values of $\eta$ and so all buyers are cash-constrained. From Lemma $2, \bar{\ell}_{h}=\bar{\ell}_{f}$. Thus we can write $q_{h}=q_{f}^{\eta}=q$ and $\ell_{h}=\ell_{f}^{\eta}=\ell$ for all $\eta$. Combining (17) and (19) yields

$$
\begin{aligned}
\phi \ell & =(1-b) q \\
\phi m_{-1} & =b q
\end{aligned}
$$

Therefore, from (21) the threshold $\eta^{*}$ is equal to $\varepsilon+(1-b) c$.

Second, we prove the existence of a fully constrained equilibrium. We distinguish three cases depending on the value of $c$ : $\eta_{1}>\varepsilon+(1-b) c, \varepsilon<\eta_{1} \leq$ $\varepsilon+(1-b) c<\eta_{2}$ and $\varepsilon+(1-b) c>\eta_{2}$. We show for the three cases that a fully constrained equilibrium exists for $\gamma \in\left[\gamma^{1}, \gamma^{2}\right]$ where $\gamma^{1}$ and $\gamma^{2}$ depend on the value of $c$. The proof proceeds as follows. First, we rewrite equilibrium equations 
by conjecturing a fully constrained equilibrium and show that $i \geq 0$ for $\gamma \geq \gamma^{1}$. Then we show that there is an interval $\left[\gamma^{1}, \gamma^{2}\right]$ such that the borrowing constraint binds for all buyers; i.e., for any value of $\eta$.

For the cases $\eta_{1} \leq \varepsilon+(1-b) c<\eta_{2}$ and $\eta_{2} \leq \varepsilon+(1-b) c$, we show that sufficiently low values of $\eta_{1}$ and $\eta_{2}$ ensure that an agent with preference shock $\eta_{1}$ or $\eta_{2}$ always prefers borrowing in order to consume the home good instead of consuming the foreign good by using only his money holdings.

Case $\eta_{1}>\varepsilon+(1-b) c$.

Using the solutions for $\eta^{*}$ and $\hat{\eta}^{*}$ stated in (22) and (26), $\eta^{*}, \hat{\eta}^{*}<\eta_{1}$. (20) and (23) can be rewritten as

$$
\gamma / \beta-1=b\left[u^{\prime}(q)+\pi_{1}\left(\eta_{1}-\varepsilon\right)+\pi_{2}\left(\eta_{2}-\varepsilon\right)-1\right]+(1-b) i
$$

and

$$
\gamma / \beta-1=b\left[u^{\prime}(\hat{q})+\pi_{1}\left(\eta_{1}-\varepsilon\right)+\pi_{2}\left(\eta_{2}-\varepsilon\right)-1\right]
$$

For a constrained equilibrium to exist, it must be that $i \geq 0$, which requires $q \geq \hat{q}$ given (43) and (44). Denote as $\gamma^{1 \prime}$ the value of $\gamma$ such that $\hat{q}=q$ and as $\gamma^{1}$ the value of $\gamma$ such that $i=0$ in a fully constrained equilibrium. From 43 and (44), $\gamma^{1}=\gamma^{1 \prime}$. Rewrite the borrowing constraint $(25)$ by conjecturing a fully constrained equilibrium for the case $\eta^{*}, \hat{\eta}^{*}<\eta_{1}$. Using (42) equation (25) becomes

$$
\begin{aligned}
& -i(1-b) q-q \\
& +\frac{\beta b}{1-\beta}\left[u(q)-q+\pi_{1}\left(\eta_{1}-\varepsilon\right) q+\pi_{2}\left(\eta_{2}-\varepsilon\right) q-\left(\pi_{1}+\pi_{2}\right)(1-b) c q\right] \\
& =\frac{\beta b}{1-\beta}\left[u(\hat{q})-\hat{q}+\pi_{1}\left(\eta_{1}-\varepsilon\right) \hat{q}+\pi_{2}\left(\eta_{2}-\varepsilon\right) \hat{q}\right]-\frac{(\gamma-\beta) \hat{q}}{1-\beta}
\end{aligned}
$$

From 45 it follows that

$$
\gamma^{1 \prime}=1+\beta b\left(\pi_{1}+\pi_{2}\right)(1-b) c
$$

Next we must ensure that $\partial i / \partial \gamma \geq 0$ for $\gamma \geq \gamma^{1 \prime}=\gamma^{1}$. Differentiate 45 with respect to $\gamma$ to get

$$
\begin{aligned}
& -\frac{\partial i}{\partial \gamma}(1-b) q-[i(1-b)+1] \frac{\partial q}{\partial \gamma} \\
& +\frac{\beta b}{1-\beta}\left\{u^{\prime}(q)-1+\pi_{1}\left(\eta_{1}-\varepsilon\right)+\pi_{2}\left(\eta_{2}-\varepsilon\right)-\left(\pi_{1}+\pi_{2}\right)(1-b) c\right\} \frac{\partial q}{\partial \gamma} \\
& =\frac{\beta b}{1-\beta}\left\{u^{\prime}(\hat{q})-1+\pi_{1}\left(\eta_{1}-\varepsilon\right)+\pi_{2}\left(\eta_{2}-\varepsilon\right)\right\} \frac{\partial \hat{q}}{\partial \gamma}-\frac{\gamma-\beta}{1-\beta} \frac{\partial \hat{q}}{\partial \gamma}-\frac{\hat{q}}{1-\beta}
\end{aligned}
$$

From 43,

$$
(1-b) \frac{\partial i}{\partial \gamma}=1 / \beta-b u^{\prime \prime}(q) \frac{\partial q}{\partial \gamma}
$$


Use (43), 44, 46) and (47) to get

$$
\frac{\partial q}{\partial \gamma}=\frac{(1-\beta) q / \beta-\hat{q}}{(1-\beta) b u^{\prime \prime}(q) q+\gamma-1-i(1-b)-\beta b\left(\pi_{1}+\pi_{2}\right)(1-b) c}
$$

and

$$
(1-b) \beta \frac{\partial i}{\partial \gamma}=\frac{\gamma-1-i(1-b)-\beta b\left(\pi_{1}+\pi_{2}\right)(1-b) c+\beta b u^{\prime \prime}(q) \hat{q}}{(1-\beta) b u^{\prime \prime}(q) q+\gamma-1-i(1-b)-\beta b\left(\pi_{1}+\pi_{2}\right)(1-b) c}
$$

From (45), we get

$$
\begin{aligned}
& \gamma-i(1-b)-1-\beta b\left(\pi_{1}+\pi_{2}\right)(1-b) c \\
& =\gamma-\beta b\left(\pi_{1}+\pi_{2}\right)(1-b) c+\frac{\beta b}{1-\beta} \frac{u(\hat{q})+\left[-1+\pi_{1}\left(\eta_{1}-\varepsilon\right)+\pi_{2}\left(\eta_{2}-\varepsilon\right)\right] \hat{q}}{q} \\
& -\frac{(\gamma-\beta) \hat{q} / q}{1-\beta}-\frac{\beta b}{1-\beta} \frac{u(q)-q+\pi_{1}\left(\eta_{1}-\varepsilon\right) q+\pi_{2}\left(\eta_{2}-\varepsilon\right) q-\left(\pi_{1}+\pi_{2}\right)(1-b) c q}{q}
\end{aligned}
$$

By the mean value theorem, $u(q)-u(\hat{q})>u^{\prime}(q)(q-\hat{q})$ for $q>\hat{q}$. Therefore, for $q>\hat{q}$ (or $i>0$ ) we verify from (49) that

$$
\gamma-i(1-b)-1-\beta b\left(\pi_{1}+\pi_{2}\right)(1-b) c<-\beta(1-b) i \frac{\hat{q}}{q}
$$

so $\gamma-i(1-b)-1-\beta b\left(\pi_{1}+\pi_{2}\right)(1-b) c$ is unambiguously negative for $i>0$ and given $\gamma^{1}$ it is equal to zero for $i=0$. Therefore from 48 it follows that $\partial i / \partial \gamma>0$ for $i \geq 0$ provided that the borrowing constraint binds. Since $\partial i / \partial \gamma>0$ at $\gamma=\gamma^{1}$, $i>0$ at $\gamma$ slightly higher than $\gamma^{1}$. In turn, this implies that $\partial i / \partial \gamma>0$ for $\gamma$ slightly higher than $\gamma^{1}$. Therefore, $i>0$ for a higher value of $\gamma$. Thus there is an interval of values of $\gamma \geq \gamma^{1}$ for which $i \geq 0$.

To conclude, we must ensure that the representative agent is credit-constrained for all values of $\eta$ as we conjectured at the beginning of the proof. We show that he is credit-constrained for a range of values of $\gamma$. Since $\eta_{1}>(1-b) c+\varepsilon$, two subcases may exist: $\eta_{1}-c-\varepsilon>0$ and $\eta_{1}-c-\varepsilon \leq 0$.

Subcase $\eta_{1}-c-\varepsilon>0$ : For the agent who consumes the home good, given (11) the multiplier of the borrowing constraint 25 is positive at $\gamma=\gamma^{1}$ if $u^{\prime}(q)-1>0$. From (43), this is the case if $\gamma / \beta-1-b \pi_{1}\left(\eta_{1}-\varepsilon\right)-b \pi_{2}\left(\eta_{2}-\varepsilon\right)>0$ at $\gamma=\gamma^{1}=\gamma^{1 \prime}$. Since $\gamma \geq 1$ and $\varepsilon \geq 0$, this inequality always holds if $1 / \beta-1-b \pi_{1} \eta_{1}-b \pi_{2} \eta_{2}>0$. Since $\eta_{1}-c-\varepsilon>0$ and $\eta_{2}>\eta_{1}$, given (15) this condition implies that the multiplier of the borrowing constraint is also positive for the agent who consumes the foreign good. It follows that if $\beta$ is sufficiently low agents are credit-constrained for all realizations of the preference shock for an interval of values of $\gamma \geq \gamma^{1}$.

Subcase $\eta_{1}-c-\varepsilon \leq 0$ : For an agent with preference shock $\eta_{1}$, given 15 the multiplier of the borrowing constraint (25) is positive at $\gamma=\gamma^{1}$ if $u^{\prime}(q)+\eta_{1}-1-$ $c-\varepsilon>0$. From (43), this is the case if $(\gamma / \beta-1) / b-\pi_{1}\left(\eta_{1}-\varepsilon\right)-\pi_{2}\left(\eta_{2}-\varepsilon\right)+\eta_{1}-$ $c-\varepsilon>0$ at $\gamma=\gamma^{1}=\gamma^{1 \prime}$. Since $\gamma \geq 1, \varepsilon \geq 0$ and $\eta_{1}>\varepsilon+(1-b) c$, this inequality 
always holds if $(1 / \beta-1) / b-\pi_{1} \eta_{1}-\pi_{2} \eta_{2}-b \eta_{1} /(1-b)>0$. Since $\eta_{2}>\eta_{1}$ and $\eta_{1}-c-\varepsilon \leq 0$, this condition implies that the multiplier of the borrowing constraint is also positive for the agent whose preference shock is $\eta_{2}$ and for the agent who consumes the home good given (11). It follows that if $\beta$ is sufficiently low agents are credit-constrained for all realizations of the preference shock for an interval of values of $\gamma \geq \gamma^{1}$.

Therefore there is an interval $\left[\gamma^{1}, \gamma^{2}\right]$ such that if $\gamma \in\left[\gamma^{1}, \gamma^{2}\right]$ then a fully constrained equilibrium in which $i \geq 0$ exists.

Case $\varepsilon<\eta_{1} \leq \varepsilon+(1-b) c<\eta_{2}$.

Using the solutions for $\eta^{*}$ and $\hat{\eta}^{*}$ stated in (22) and (26), $\eta^{*}>\eta_{1}$ and $\hat{\eta}^{*}<\eta_{1}$. (20) and (23) can be rewritten as

$$
\gamma / \beta=b u^{\prime}(q)+b \pi_{2}\left(\eta_{2}-\varepsilon\right)+(1-b)(1+i)
$$

and

$$
\gamma / \beta-1=b\left[u^{\prime}(\hat{q})+\pi_{1}\left(\eta_{1}-\varepsilon\right)+\pi_{2}\left(\eta_{2}-\varepsilon\right)-1\right]
$$

For a constrained equilibrium to exist, it must be that $i \geq 0$. Denote as $\gamma^{1 \prime}$ the value of $\gamma$ such that $\hat{q}=q$ and as $\gamma^{1}$ the value of $\gamma$ such that $i=0$ in a fully constrained equilibrium. From (50) and (51) it follows that $(1-b) i=b \pi_{1}\left(\eta_{1}-\varepsilon\right)$ at $\gamma=\gamma^{1 \prime}$ so $i>0$. Rewrite the borrowing constraint (25) by conjecturing a fully constrained equilibrium for the case $\eta_{1} \leq \eta^{*}<\eta_{2}$ and $\hat{\eta}^{*}<\eta_{1}$. Using (42) equation (25) becomes

$$
\begin{aligned}
& -i(1-b) q-q+\frac{\beta b}{1-\beta}\left\{u(q)-q+\pi_{2}\left[\eta_{2}-\varepsilon-(1-b) c\right] q\right\} \\
& =\frac{\beta b}{1-\beta}\left\{u(\hat{q})+\left[-1+\pi_{1}\left(\eta_{1}-\varepsilon\right)+\pi_{2}\left(\eta_{2}-\varepsilon\right)\right] \hat{q}\right\}-\frac{(\gamma-\beta) \hat{q}}{1-\beta}
\end{aligned}
$$

From (52) it follows that

$$
\gamma^{1 \prime}=1+\beta b \pi_{2}(1-b) c+b \pi_{1}\left(\eta_{1}-\varepsilon\right)
$$

Next we must ensure that $\partial i / \partial \gamma \geq 0$ for $\gamma \geq \gamma^{1 \prime}$. Differentiate 52 with respect to $\gamma$ to get

$$
\begin{aligned}
& -\frac{\partial i}{\partial \gamma}(1-b) q-[i(1-b)+1] \frac{\partial q}{\partial \gamma}+\frac{\beta b}{1-\beta}\left\{u^{\prime}(q)-1+\pi_{2}\left[\eta_{2}-\varepsilon-(1-b) c\right]\right\} \frac{\partial q}{\partial \gamma} \\
& =\frac{\beta b}{1-\beta}\left\{u^{\prime}(\hat{q})-1+\pi_{1}\left(\eta_{1}-\varepsilon\right)+\pi_{2}\left(\eta_{2}-\varepsilon\right)\right\} \frac{\partial \hat{q}}{\partial \gamma}-\frac{\gamma-\beta}{1-\beta} \frac{\partial \hat{q}}{\partial \gamma}-\frac{\hat{q}}{1-\beta}
\end{aligned}
$$

From (50),

$$
(1-b) \frac{\partial i}{\partial \gamma}=1 / \beta-b u^{\prime \prime}(q) \frac{\partial q}{\partial \gamma}
$$


Use (50), (51), (54) and (55) to get

$$
\frac{\partial q}{\partial \gamma}=\frac{(1-\beta) q / \beta-\hat{q}}{(1-\beta) b u^{\prime \prime}(q) q+\gamma-1-(1-b) i-\beta b \pi_{2}(1-b) c}
$$

and

$$
(1-b) \beta \frac{\partial i}{\partial \gamma}=\frac{\beta b u^{\prime \prime}(q) \hat{q}+\gamma-1-(1-b) i-\beta b \pi_{2}(1-b) c}{(1-\beta) b u^{\prime \prime}(q) q+\gamma-1-(1-b) i-\beta b \pi_{2}(1-b) c}
$$

From (52), we get

$$
\begin{aligned}
& \gamma-i(1-b)-1-\beta b \pi_{2}(1-b) c \\
& =\gamma-\beta b \pi_{2}(1-b) c+\frac{\beta b}{1-\beta} \frac{u(\hat{q})+\left[-1+\pi_{1}\left(\eta_{1}-\varepsilon\right)+\pi_{2}\left(\eta_{2}-\varepsilon\right)\right] \hat{q}}{q}-\frac{(\gamma-\beta) \hat{q} / q}{1-\beta} \\
& -\frac{\beta b}{1-\beta} \frac{u(q)-q+\pi_{2}\left[\eta_{2}-\varepsilon-(1-b) c\right] q}{q}
\end{aligned}
$$

By the mean value theorem, $u(q)-u(\hat{q})>u^{\prime}(q)(q-\hat{q})$ for $q>\hat{q}$. Therefore, for $q>\hat{q}$ (or $(1-b) i>b \pi_{1}\left(\eta_{1}-\varepsilon\right)$ ) we verify from (57) that

$$
\gamma-i(1-b)-1-\beta b \pi_{2}(1-b) c<\beta\left[b \pi_{1}\left(\eta_{1}-\varepsilon\right)-(1-b) i\right] \hat{q} / q
$$

so $\gamma-i(1-b)-1-\beta b \pi_{2}(1-b) c$ is unambiguously negative for $(1-b) i>$ $b \pi_{1}\left(\eta_{1}-\varepsilon\right)$ and given $\gamma^{1 \prime}$ it is equal to zero at $(1-b) i=b \pi_{1}\left(\eta_{1}-\varepsilon\right)$. Therefore from (56) it follows that $\partial i / \partial \gamma>0$ for $i \geq b \pi_{1}\left(\eta_{1}-\varepsilon\right) /(1-b)>0$ provided that the borrowing constraint binds. Since $\partial i / \partial \gamma>0$ at $\gamma=\gamma^{1 \prime},(1-b) i$ is slightly higher than $b \pi_{1}\left(\eta_{1}-\varepsilon\right)$ for $\gamma$ slightly higher than $\gamma^{1 \prime}$. In turn, this implies that $\partial i / \partial \gamma>0$ for $\gamma$ slightly higher than $\gamma^{1 \prime}$. Therefore $i>b \pi_{1}\left(\eta_{1}-\varepsilon\right) /(1-b)>0$ for a higher value of $\gamma$. Since $i>0$ at $\gamma=\gamma^{1 \prime}, \gamma^{1}<\gamma^{1 \prime}$ and there is an interval of values of $\gamma \geq \gamma^{1}$ for which $i \geq 0$.

To conclude, we must ensure that the representative agent is credit-constrained for all values of $\eta$ as we conjectured at the beginning of the proof. We show that he is credit-constrained for a range of values of $\gamma$. Since $\varepsilon<\eta_{1} \leq \varepsilon+(1-b) c<\eta_{2}$, two subcases may exist: $\eta_{2}-c-\varepsilon>0$ and $\eta_{2}-c-\varepsilon \leq 0$.

Subcase $\eta_{2}-c-\varepsilon>0$ : For the agent who consumes the home good, given (11) the multiplier of the borrowing constraint (25) is positive if $u^{\prime}(q)-1-i>0$. From (50), at $\gamma=\gamma^{1 \prime}$ this is the case if $\gamma / \beta-1-b \pi_{2}\left(\eta_{2}-\varepsilon\right)-b \pi_{1}\left(\eta_{1}-\varepsilon\right) /(1-b)>0$. Since $\gamma \geq 1$ and $\varepsilon \geq 0$, this always holds if $1 / \beta-1-b \pi_{2} \eta_{2}-b \pi_{1} \eta_{1} /(1-b)>0$. It is straightforward that this condition also implies that $u^{\prime}(q)-1-i>0$ for $0 \leq(1-b) i \leq b \pi_{1}\left(\eta_{1}-\varepsilon\right)$ and $\gamma \in\left[\gamma^{1}, \gamma^{1 \prime}\right]$. Since $\eta_{2}-c-\varepsilon>0$, given 15 this condition also implies that the multiplier of the borrowing constraint is also positive for the agent who consumes the foreign good. It follows that if $\beta$ is sufficiently low agents are credit constrained for all realizations of the preference shock for an interval of values of $\gamma \geq \gamma^{1}$. 
Subcase $\eta_{2}-c-\varepsilon \leq 0$ : For an agent with preference shock $\eta_{2}$, given (15) the multiplier of the borrowing constraint (25) is positive if $u^{\prime}(q)-1-i+\eta_{2}-$ $c-\varepsilon>0$. From (50), at $\gamma=\gamma^{1 \prime}$ this is the case if $(\gamma / \beta-1) / b-\pi_{2}\left(\eta_{2}-\varepsilon\right)-$ $\pi_{1}\left(\eta_{1}-\varepsilon\right) /(1-b)+\eta_{2}-c-\varepsilon>0$. Since $\gamma \geq 1, \varepsilon \geq 0$ and $\eta_{2}>(1-b) c+\varepsilon$, this always holds if $(1 / \beta-1) / b-\pi_{2} \eta_{2}-\pi_{1} \eta_{1} /(1-b)+b \eta_{2} /(1-b)>0$. It is straightforward that this condition also implies that $u^{\prime}(q)-1-i+\eta_{2}-c-\varepsilon>0$ for $0 \leq(1-b) i \leq b \pi_{1}\left(\eta_{1}-\varepsilon\right)$ and $\gamma \in\left[\gamma^{1}, \gamma^{1 \prime}\right]$. Since $\eta_{2}-c-\varepsilon<0$, given (11) this condition also implies that the multiplier of the borrowing constraint is also positive for the agent who consumes the foreign good. It follows that if $\beta$ is sufficiently low agents are credit constrained for all realizations of the preference shock for an interval of values of $\gamma \geq \gamma^{1}$.

Finally note that an agent with $\eta=\eta_{1}$ could prefer to consume the foreign good by using only his money holdings instead of borrowing and consuming the home good, but this possibility can be dismissed. That is, the following condition is satisfied

$$
u(q)-\phi \ell(1+i) \geq u\left(m_{-1}\right)+\left(\eta_{1}-\varepsilon\right) m_{-1}
$$

From (42), this expression can be written as

$$
u(q)-(1-b) q(1+i) \geq u(b q)+\left(\eta_{1}-\varepsilon\right) b q
$$

Since $u(q)-u(b q)>u^{\prime}(q)(1-b) q$ and in a fully constrained equilibrium $i \leq$ $u^{\prime}(q)-1$, it follows that it is always possible to define a value $\bar{\eta}_{1}$ such that if $\eta_{1} \leq \bar{\eta}_{1}$ the above inequality holds.

Therefore there is an interval $\left[\gamma^{1}, \gamma^{2}\right]$ such that if $\gamma \in\left[\gamma^{1}, \gamma^{2}\right]$ then a fully constrained equilibrium in which $i \geq 0$ exists.

Case $\eta_{2}<\varepsilon+(1-b) c$.

Using the solutions for $\eta^{*}$ and $\hat{\eta}^{*}$ stated in (22) and (26), $\eta^{*}>\eta_{2}$ and $\hat{\eta}^{*}<\eta_{1}$. (20) and (23) can be rewritten as

$$
\gamma / \beta-1=b\left[u^{\prime}(q)-1\right]+(1-b) i
$$

and

$$
\gamma / \beta-1=b\left[u^{\prime}(\hat{q})+\pi_{1}\left(\eta_{1}-\varepsilon\right)+\pi_{2}\left(\eta_{2}-\varepsilon\right)-1\right]
$$

For a constrained equilibrium to exist, it must be that $i \geq 0$. Denote as $\gamma^{1 \prime}$ the value of $\gamma$ such that $\hat{q}=q$ and as $\gamma^{1}$ the value of $\gamma$ such that $i=0$ in a fully constrained equilibrium. From (58) and (59), $(1-b) i=b\left[\pi_{1}\left(\eta_{1}-\varepsilon\right)+\pi_{2}\left(\eta_{2}-\varepsilon\right)\right]$ at $\gamma=\gamma^{1 \prime}$. Rewrite the borrowing constraint 25 by conjecturing a fully constrained equilibrium for the case $\eta^{*}>\eta_{2}$ and $\hat{\eta}^{*}<\eta_{1}$. Using (42) it becomes

$$
\begin{aligned}
& -i(1-b) q-q+\frac{\beta b}{1-\beta}[u(q)-q] \\
& =\frac{\beta b}{1-\beta}\left[u(\hat{q})-\hat{q}+\pi_{1}\left(\eta_{1}-\varepsilon\right) \hat{q}+\pi_{2}\left(\eta_{2}-\varepsilon\right) \hat{q}\right]-\frac{(\gamma-\beta) \hat{q}}{1-\beta}
\end{aligned}
$$


From 60 it follows that

$$
\gamma^{1 \prime}=1+b\left[\pi_{1}\left(\eta_{1}-\varepsilon\right)+\pi_{2}\left(\eta_{2}-\varepsilon\right)\right]
$$

Next we must ensure that $\partial i / \partial \gamma \geq 0$ for $\gamma \geq \gamma^{1 \prime}$. Differentiate 60 with respect to $\gamma$ to get

$$
\begin{aligned}
& -\frac{\partial i}{\partial \gamma}(1-b) q-[i(1-b)+1] \frac{\partial q}{\partial \gamma}+\frac{\beta b}{1-\beta}\left[u^{\prime}(q)-1\right] \frac{\partial q}{\partial \gamma} \\
& =\frac{\beta b}{1-\beta}\left\{u^{\prime}(\hat{q})-1+\pi_{1}\left(\eta_{1}-\varepsilon\right)+\pi_{2}\left(\eta_{2}-\varepsilon\right)\right\} \frac{\partial \hat{q}}{\partial \gamma}-\frac{\gamma-\beta}{1-\beta} \frac{\partial \hat{q}}{\partial \gamma}-\frac{\hat{q}}{1-\beta}
\end{aligned}
$$

From (58),

$$
(1-b) \frac{\partial i}{\partial \gamma}=1 / \beta-b u^{\prime \prime}(q) \frac{\partial q}{\partial \gamma}
$$

Use (58), (59), (61) and (62) to get

$$
\frac{\partial q}{\partial \gamma}=\frac{(1-\beta) q / \beta-\hat{q}}{\gamma-1-i(1-b)+(1-\beta) b u^{\prime \prime}(q) q}
$$

and

$$
(1-b) \beta \frac{\partial i}{\partial \gamma}=\frac{\gamma-1-i(1-b)+\beta b u^{\prime \prime}(q) \hat{q}}{\gamma-1-i(1-b)+(1-\beta) b u^{\prime \prime}(q) q}
$$

From 60), we get

$$
\begin{aligned}
& \gamma-i(1-b)-1+\frac{\beta b}{1-\beta} \frac{u(q)-q}{q} \\
& =\gamma+\frac{\beta b}{1-\beta} \frac{u(\hat{q})-\hat{q}+\pi_{1}\left(\eta_{1}-\varepsilon\right) \hat{q}+\pi_{2}\left(\eta_{2}-\varepsilon\right) \hat{q}}{q}-\frac{(\gamma-\beta) \hat{q} / q}{1-\beta}
\end{aligned}
$$

By the mean value theorem, $u(q)-u(\hat{q})>u^{\prime}(q)(q-\hat{q})$ for $q>\hat{q}$. Therefore, for $q>\hat{q}$ (or $i>b\left[\pi_{1}\left(\eta_{1}-\varepsilon\right)+\pi_{2}\left(\eta_{2}-\varepsilon\right)\right] /(1-b)$ ) we verify from (64) that

$$
\gamma-i(1-b)-1<\beta\left\{b\left[\pi_{1}\left(\eta_{1}-\varepsilon\right)+\pi_{2}\left(\eta_{2}-\varepsilon\right)\right]-(1-b) i\right\} \hat{q} / q
$$

so $\gamma-i(1-b)-1$ is unambiguously negative for $(1-b) i>b\left[\pi_{1}\left(\eta_{1}-\varepsilon\right)+\pi_{2}\left(\eta_{2}-\varepsilon\right)\right]$ and given $\gamma^{1 \prime}$ it is equal to zero at $(1-b) i=b\left[\pi_{1}\left(\eta_{1}-\varepsilon\right)+\pi_{2}\left(\eta_{2}-\varepsilon\right)\right]$. Therefore from (63) it follows that $\partial i / \partial \gamma>0$ for $i \geq b\left[\pi_{1}\left(\eta_{1}-\varepsilon\right)+\pi_{2}\left(\eta_{2}-\varepsilon\right)\right]>0$ provided that the borrowing constraint binds. Since $\partial i / \partial \gamma>0$ at $\gamma=\gamma^{1 /},(1-b) i$ is slightly higher than $b\left[\pi_{1}\left(\eta_{1}-\varepsilon\right)+\pi_{2}\left(\eta_{2}-\varepsilon\right)\right]$ for $\gamma$ slightly higher than $\gamma^{1 \prime}$. In turn, this implies that $\partial i / \partial \gamma>0$ for $\gamma$ slightly higher than $\gamma^{1 \prime}$. Therefore $i>b\left[\pi_{1}\left(\eta_{1}-\varepsilon\right)+\pi_{2}\left(\eta_{2}-\varepsilon\right)\right] /(1-b)>0$ for a higher value of $\gamma$. Since $i>0$ at $\gamma=\gamma^{1 \prime}, \gamma^{1}<\gamma^{1 \prime}$ and there is an interval of values of $\gamma \geq 0$ for which $i \geq 0$.

To conclude, we must ensure that the representative agent is credit-constrained for all values of $\eta$ as we conjectured at the beginning of the proof. When $\eta_{2}<$ 
$\varepsilon+(1-b) c$, the agent consumes the home good for all realizations of the preference shock. Given (11), the multiplier of the borrowing constraint (25) is positive if $u^{\prime}(q)-1-i>0$. From (58), at $\gamma=\gamma^{1 \prime}$ this is the case if $\gamma / \beta-1-$ $b\left[\pi_{1}\left(\eta_{1}-\varepsilon\right)+\pi_{2}\left(\eta_{2}-\varepsilon\right)\right] /(1-b)>0$. Since $\gamma \geq 1$ and $\varepsilon \geq 0$, this always holds if $1 / \beta-1-b\left(\pi_{1} \eta_{1}+\pi_{2} \eta_{2}\right) /(1-b)>0$. It is straightforward that this condition also implies that $u^{\prime}(q)-1-i>0$ for $0 \leq(1-b) i \leq b\left[\pi_{1}\left(\eta_{1}-\varepsilon\right)+\pi_{2}\left(\eta_{2}-\varepsilon\right)\right]$ and $\gamma \in\left[\gamma^{1}, \gamma^{1 \prime}\right]$. It follows that if $\beta$ is sufficiently low agents are credit constrained for all realizations of the preference shock for an interval of values of $\gamma \geq \gamma^{1}$.

Finally note that an agent with $\eta=\eta_{1}, \eta_{2}$ could prefer to consume the foreign good by using only his money holdings instead of borrowing and consuming the home good, but this possibility can be dismissed. That is, the following condition is satisfied

$$
u(q)-\phi \ell(1+i) \geq u\left(m_{-1}\right)+\left(\eta_{2}-\varepsilon\right) m_{-1}
$$

From (42), this expression can be written as

$$
u(q)-(1-b) q(1+i) \geq u(b q)+\left(\eta_{2}-\varepsilon\right) b q
$$

Since $u(q)-u(b q)>u^{\prime}(q)(1-b) q$ and in a fully constrained equilibrium $i \leq$ $u^{\prime}(q)-1$, it follows that it is always possible to define a value $\bar{\eta}_{2}$ such that if $\eta_{2} \leq \bar{\eta}_{2}$ the above inequality holds. Further, the above inequality implies that $u(q)-(1-b) q(1+i) \geq u(b q)+\left(\eta_{1}-\varepsilon\right) b q$ since $\eta_{2}>\eta_{1}$.

Therefore there is an interval $\left[\gamma^{1}, \gamma^{2}\right]$ such that if $\gamma \in\left[\gamma^{1}, \gamma^{2}\right]$ then a fully constrained equilibrium in which $i \geq 0$ exists.

Proof of Proposition 3 . Given (35), 20) can be written as

$$
\gamma / \beta=u^{\prime}\left(q_{f}^{\eta}\right)+\eta-\varepsilon-\left(1-b \sum_{\eta>\eta^{*}} \pi_{\eta}\right) c
$$

Hence

$$
\frac{\partial q_{f}^{\eta}}{\partial \varepsilon}=\frac{1}{u^{\prime \prime}\left(q_{f}^{\eta}\right)}
$$

so that $\partial q_{f}^{\eta} / \partial \varepsilon<0$. From $(35)$ and $(65), \partial q_{h} / \partial \varepsilon=0$. From $(37)$ and $(38)$, we get

$$
\frac{\partial\left(\phi \ell_{h}\right)}{\partial \varepsilon}=-b \sum_{\eta>\eta^{*}} \pi_{\eta} \frac{\partial q_{f}^{\eta}}{\partial \varepsilon}
$$

and

$$
\frac{\partial\left(\phi \ell_{f}^{\eta}\right)}{\partial \varepsilon}=\left(1-b \sum_{\eta>\eta^{*}} \pi_{\eta}\right) \frac{\partial q_{f}^{\eta}}{\partial \varepsilon}
$$

Given 65, we get $\partial\left(\phi \ell_{h}\right) / \partial \varepsilon>0$ and $\partial\left(\phi \ell_{f}^{\eta}\right) / \partial \varepsilon<0$. 
Differentiating 27) with respect to $\varepsilon$ yields

$$
\frac{\partial \mathcal{W}}{\partial \varepsilon}=\frac{b}{1-\beta} \sum_{\eta>\eta^{*}} \pi_{\eta}\left\{\left[u^{\prime}\left(q_{f}^{\eta}\right)-1+\eta-\varepsilon-c+b \sum_{\eta>\eta^{*}} \pi_{\eta} c\right] \frac{\partial q_{f}^{\eta}}{\partial \varepsilon}-q_{f}^{\eta}\right\}
$$

Since $u^{\prime}\left(q_{f}^{\eta}\right)-1+\eta-\varepsilon-c>0$ for all $\eta>\eta^{*}$ from 35 and $\partial q_{f}^{\eta} / \partial \varepsilon<0$ from (65), it follows that $\partial \mathcal{W} / \partial \varepsilon<0$.

Proof of Proposition 4. Let $c<\left(\eta_{1}-\varepsilon\right) /(1-b)$ and consider a fully constrained equilibrium in which $\lambda_{h}^{\eta}, \lambda_{f}^{\eta}>0$ and the borrowing constraint 25 holds with equality. As in the proof of Proposition 2, we can set $\phi \ell_{h}=\phi \ell_{f}^{\eta}=\phi \ell$ and $q_{h}=q_{f}^{\eta}=q$ for all $\eta$. Given 26 and 42 , welfare defined in 27) becomes

$$
\mathcal{W}\left(\frac{b}{1-\beta}\right)^{-1}=u(q)+\left(-1+\pi_{1} \eta_{1}+\pi_{2} \eta_{2}\right) q-\left(\pi_{1}+\pi_{2}\right)[\varepsilon+(1-b) c] q
$$

Differentiate the borrowing constraint for the case $c<\left(\eta_{1}-\varepsilon\right) /(1-b)$ stated in 45 with respect to $\varepsilon$ to get

$$
\begin{aligned}
& -[1+(1-b) i] \frac{\partial q}{\partial \varepsilon}-(1-b) \frac{\partial i}{\partial \varepsilon} q-\frac{\beta b\left(\pi_{1}+\pi_{2}\right)}{1-\beta} q \\
& +\frac{\beta b}{1-\beta}\left\{u^{\prime}(q)-1+\pi_{1} \eta_{1}+\pi_{2} \eta_{2}-\left(\pi_{1}+\pi_{2}\right)[\varepsilon+(1-b) c]\right\} \frac{\partial q}{\partial \varepsilon} \\
& =\frac{\beta b}{1-\beta}\left[u^{\prime}(\hat{q})-1+\pi_{1}\left(\eta_{1}-\varepsilon\right)+\pi_{2}\left(\eta_{2}-\varepsilon\right)\right] \frac{\partial \hat{q}}{\partial \varepsilon}-\frac{\beta b\left(\pi_{1}+\pi_{2}\right)}{1-\beta} \hat{q}-\frac{\gamma-\beta}{1-\beta} \frac{\partial \hat{q}}{\partial \varepsilon}
\end{aligned}
$$

Differentiating (43) with respect to $\varepsilon$ yields

$$
(1-b) \frac{\partial i}{\partial \varepsilon}=-b u^{\prime \prime}(q) \frac{\partial q}{\partial \varepsilon}+b\left(\pi_{1}+\pi_{2}\right)
$$

Rewrite (67) using 43), 44 and (68) to get

$$
\frac{\partial q}{\partial \varepsilon}=\frac{b\left(\pi_{1}+\pi_{2}\right)[(1-\beta) q+\beta(q-\hat{q})]}{\gamma-1-(1-b) i-\beta b\left(\pi_{1}+\pi_{2}\right)(1-b) c+(1-\beta) b q u^{\prime \prime}(q)}
$$

From (43) and (44), $q=\hat{q}$ when $i=0$ and $q>\hat{q}$ when $i>0$. From the proof of Proposition 2, when $c<\left(\eta_{1}-\varepsilon\right) /(1-b)$ the value of $\gamma$ such that $i=0$ and $q=\hat{q}$ is $\gamma^{1}=1+\beta b\left(\pi_{1}+\pi_{2}\right)(1-b) c$. Further, $q \geq \hat{q}$ for $\gamma \in\left[\gamma^{1}, \gamma^{2}\right]$. Therefore, the numerator at the right-hand side in $\sqrt{69}$ is positive for $\gamma \in\left[\gamma^{1}, \gamma^{2}\right]$. From the proof of Proposition 2, it can be deduced that the denominator at the right-hand side in 69 is negative for $\gamma \in\left[\gamma^{1}, \gamma^{2}\right]$. It follows that in a fully constrained equilibrium $\partial q / \partial \varepsilon<0$ for $\gamma \in\left[\gamma^{1}, \gamma^{2}\right]$. Since $\phi \ell_{h}=\phi \ell_{f}^{\eta}=\phi \ell=(1-b) q$ for all $\eta$ from 42 , $\partial(\phi \ell) / \partial \varepsilon<0$.

Differentiating (66) with respect to $\varepsilon$ yields

$$
\frac{\partial \mathcal{W}}{\partial \varepsilon}\left(\frac{b}{1-\beta}\right)^{-1}=\left\{u^{\prime}(q)-1+\pi_{1} \eta_{1}+\pi_{2} \eta_{2}-\left(\pi_{1}+\pi_{2}\right)[\varepsilon+(1-b) c]\right\} \frac{\partial q}{\partial \varepsilon}-\left(\pi_{1}+\pi_{2}\right) q
$$


Since $\eta_{1}, \eta_{2}>\varepsilon+(1-b) c$ and $\partial q / \partial \varepsilon<0$ from $(69)$, it follows that $\partial \mathcal{W} / \partial \varepsilon<0$.

Proof of Proposition 5. For this proof we distinguish two cases, $\varepsilon+(1-b) c>\eta_{2}$ and $\varepsilon<\eta_{1} \leq \varepsilon+(1-b) c<\eta_{2}$. In the first case showing that $\partial \mathcal{W} / \partial \varepsilon>0$ is straightforward since the non-defaulter consumes only the home good and hence does not incur conversion costs. For the second case it is shown that $\partial \mathcal{W} / \partial \varepsilon>0$ holds for $\pi_{2}$ sufficiently low.

Consider a fully constrained equilibrium in which $\lambda_{h}^{\eta}, \lambda_{f}^{\eta}>0$ and the borrowing constraint (25) holds with equality. As in the proof of Proposition 2, we can set $\phi \ell_{h}=\phi \ell_{f}^{\eta}=\phi \ell$ and $q_{h}=q_{f}^{\eta}=q$ for all $\eta$.

Case $\varepsilon+(1-b) c>\eta_{2}$.

Given (26), welfare defined in (27) becomes

$$
\mathcal{W}\left(\frac{b}{1-\beta}\right)^{-1}=u(q)-q
$$

Differentiate the borrowing constraint for the case $\varepsilon+(1-b) c>\eta_{2}$ stated in (60) with respect to $\varepsilon$ to get

$$
\begin{aligned}
& -(1-b) \frac{\partial i}{\partial \varepsilon} q+\frac{\beta b\left(\pi_{1}+\pi_{2}\right)}{1-\beta} \hat{q}-[1+(1-b) i] \frac{\partial q}{\partial \varepsilon} \\
& +\frac{\beta b}{1-\beta}\left[u^{\prime}(q)-1\right] \frac{\partial q}{\partial \varepsilon} \\
& =\frac{\beta b}{1-\beta}\left\{u^{\prime}(\hat{q})-1+\left[\pi_{1}\left(\eta_{1}-\varepsilon\right)+\pi_{2}\left(\eta_{2}-\varepsilon\right)\right]\right\} \frac{\partial \hat{q}}{\partial \varepsilon}-\frac{\gamma-\beta}{1-\beta} \frac{\partial \hat{q}}{\partial \varepsilon}
\end{aligned}
$$

Differentiating (58) with respect to $\varepsilon$ yields

$$
(1-b) \frac{\partial i}{\partial \varepsilon}=-b u^{\prime \prime}(q) \frac{\partial q}{\partial \varepsilon}
$$

Rewrite (71) using (58), (59) and $(72)$

$$
\frac{\partial q}{\partial \varepsilon}=\frac{-\beta b\left(\pi_{1}+\pi_{2}\right) \hat{q} /(1-\beta)}{b u^{\prime \prime}(q) q+[\gamma-1-(1-b) i] /(1-\beta)}
$$

From the proof of Proposition 2 , it can be deduced that the denominator at the right-hand side of $(73)$ is negative. Since the numerator at the right-hand side of (73) is also negative, it follows that in a fully constrained equilibrium $\partial q / \partial \varepsilon>0$. Since $\phi \ell_{h}=\phi \ell_{f}^{\eta}=\phi \ell=(1-b) q$ for all $\eta$ from 442 , it follows that $\partial(\phi \ell) / \partial \varepsilon>0$.

Differentiating (70) with respect to $\varepsilon$ yields

$$
\frac{\partial \mathcal{W}}{\partial \varepsilon}\left(\frac{b}{1-\beta}\right)^{-1}=\left[u^{\prime}(q)-1\right] \frac{\partial q}{\partial \varepsilon}
$$

Since $\partial q / \partial \varepsilon>0$ from $(73), 74$ implies that $\partial \mathcal{W} / \partial \varepsilon>0$. 
Case $\varepsilon<\eta_{1} \leq \varepsilon+(1-b) c<\eta_{2}$.

Given (26) and (42), welfare defined in (27) becomes

$$
\mathcal{W}\left(\frac{b}{1-\beta}\right)^{-1}=u(q)-q+\pi_{2}\left[\eta_{2}-\varepsilon-(1-b) c\right] q
$$

Differentiate the borrowing constraint for the case $\varepsilon<\eta_{1} \leq \varepsilon+(1-b) c<\eta_{2}$ stated in 52 with respect to $\varepsilon$ to get

$$
\begin{aligned}
& -(1-b) \frac{\partial i}{\partial \varepsilon} q-\frac{\beta b}{1-\beta}\left[\pi_{2} q-\left(\pi_{1}+\pi_{2}\right) \hat{q}\right] \\
& -[1+(1-b) i] \frac{\partial q}{\partial \varepsilon}+\frac{\beta b}{1-\beta}\left\{u^{\prime}(q)-1+\pi_{2}\left[\eta_{2}-\varepsilon-(1-b) c\right]\right\} \frac{\partial q}{\partial \varepsilon} \\
& =\frac{\beta b}{1-\beta}\left\{u^{\prime}(\hat{q})-1+\left[\pi_{1}\left(\eta_{1}-\varepsilon\right)+\pi_{2}\left(\eta_{2}-\varepsilon\right)\right]\right\} \frac{\partial \hat{q}}{\partial \varepsilon}-\frac{\gamma-\beta}{1-\beta} \frac{\partial \hat{q}}{\partial \varepsilon}
\end{aligned}
$$

Differentiating (50) with respect to $\varepsilon$ yields

$$
(1-b) \frac{\partial i}{\partial \varepsilon}=-b u^{\prime \prime}(q) \frac{\partial q}{\partial \varepsilon}+b \pi_{2}
$$

Rewrite (76) using (50), 51) and (77)

$$
\frac{\partial q}{\partial \varepsilon}=\frac{b \pi_{2} q+\beta b\left[\pi_{2} q-\left(\pi_{1}+\pi_{2}\right) \hat{q}\right] /(1-\beta)}{b u^{\prime \prime}(q) q+\left[\gamma-1-(1-b) i-\beta b(1-b) \pi_{2} c\right] /(1-\beta)}
$$

From the proof of Proposition 2, it can be deduced that the denominator at the right-hand side of 78 is negative. At $\gamma=\gamma^{1 \prime}, q=\hat{q}$ and hence the numerator at the right-hand side of $(78)$ is negative if $\pi_{2}-\beta \pi_{1} /(1-\beta)<0$. Therefore, $\partial q / \partial \varepsilon>0$ at $\gamma=\gamma^{1 \prime}$ if $\pi_{2}$ is sufficiently low. Since $q$ is increasing in $\varepsilon$ as long as the numerator at the right-hand side of $(78)$ is negative and $\hat{q}$ is decreasing in $\varepsilon$ given (51), the numerator at the right-hand side of $(78)$ is increasing in $\varepsilon$. Define $\gamma^{2 \prime}$ the value of $\gamma$ such that the numerator at the right-hand side of (78) is zero given $\{q, \hat{q}, i\}$ that solve (50), (51) and $(52)$. In addition, let $\bar{\gamma}^{2}=\min \left(\gamma^{2}, \gamma^{2 \prime}\right)$. Then in a fully constrained equilibrium $\partial q / \partial \varepsilon>0$ for $\gamma \in\left[\gamma^{1}, \bar{\gamma}^{2}\right]$. Since $\phi \ell_{h}=$ $\phi \ell_{f}^{\eta}=\phi \ell=(1-b) q$ for all $\eta$ from $[42), \partial(\phi \ell) / \partial \varepsilon>0$ for $\gamma \in\left[\gamma^{1}, \bar{\gamma}^{2}\right]$.

Differentiating (75) with respect to $\varepsilon$ yields

$$
\frac{\partial \mathcal{W}}{\partial \varepsilon}\left(\frac{b}{1-\beta}\right)^{-1}=\left\{u^{\prime}(q)-1+\pi_{2}\left[\eta_{2}-\varepsilon-(1-b) c\right]\right\} \frac{\partial q}{\partial \varepsilon}-\pi_{2} q
$$

Using (78) for $\gamma \in\left[\gamma^{1}, \gamma^{1 \prime}\right]$ with $\gamma^{1 \prime}$ stated in 53 it follows that

$$
\frac{\partial \mathcal{W}}{\partial \varepsilon}\left(\frac{b}{1-\beta}\right)^{-1}>\frac{u^{\prime}(q)-1+\pi_{2}\left[\eta_{2}-\varepsilon-(1-b) c\right]}{-u^{\prime \prime}(q)}\left(\frac{\beta \pi_{1}}{1-\beta}-\pi_{2}\right)-\pi_{2} q
$$

Since assumed preferences satisfy $-u^{\prime \prime}(q) q \leq u^{\prime}(q)$ and $\eta_{2}-\varepsilon-(1-b) c>0$, a sufficient condition for $\partial \mathcal{W} / \partial \varepsilon>0$ for $\gamma \in\left[\gamma^{1}, \gamma^{1 \prime}\right]$ is

$$
\frac{u^{\prime}(q)-1}{u^{\prime}(q)}\left(\frac{\beta \pi_{1}}{1-\beta}-\pi_{2}\right)-\pi_{2}>0
$$


The left-hand side at 80 is positive at $\pi_{2}=0$ and given 50 is decreasing in $\pi_{2}$ for $\gamma \in\left[\gamma^{1}, \gamma^{1 \prime}\right]$. Therefore there is a value $\bar{\pi}_{2}>0$ such that if $\pi_{2} \leq \bar{\pi}_{2}$ the left-hand side in 80$]$ is positive for $\gamma \in\left[\gamma^{1}, \gamma^{1 /}\right]$. Since condition 80 is sufficient (but not necessary) there is $\hat{\pi}_{2}>\bar{\pi}_{2}>0$ and $\hat{\gamma}^{2}>\gamma^{1 \prime}$ such that if $\pi_{2} \leq \hat{\pi}_{2}$ then $\partial \mathcal{W} / \partial \varepsilon>0$ for $\gamma \in\left[\gamma^{1}, \hat{\gamma}^{2}\right]$.

Proof of Proposition 8. We proceed in three steps to show that the amount of credit is decreasing in $c$. Consider two cases: $\varepsilon=0$ and $\varepsilon>0$. First, we show that $q$ is decreasing in $c$ from some value $c_{0}$ up to some value $c<\eta_{1} /(1-b)$ in the case $\varepsilon=0$ and up to some value $c<\left(\eta_{1}-\varepsilon\right) /(1-b)$ in the case $\varepsilon>0$. To prove that an increase in $c$ entails a decrease in credit in a fully constrained equilibrium in which $\varepsilon+(1-b) c \leq \eta_{1}$ with $\varepsilon \geq 0$, differentiate the borrowing constraint stated in (45) with respect to $c$ :

$$
\begin{aligned}
& -[(1-b) i+1] \frac{\partial q}{\partial c}-(1-b) q \frac{\partial i}{\partial c}-\frac{\beta b}{1-\beta}\left(\pi_{1}+\pi_{2}\right)(1-b) q \\
& +\frac{\beta b}{1-\beta}\left\{u^{\prime}(q)-1+\pi_{1} \eta_{1}+\pi_{2} \eta_{2}-\left(\pi_{1}+\pi_{2}\right)[\varepsilon+(1-b) c]\right\} \frac{\partial q}{\partial c}=0
\end{aligned}
$$

From 43 we get

$$
(1-b) \frac{\partial i}{\partial c}=-b u^{\prime \prime}(q) \frac{\partial q}{\partial c}
$$

Use (43) and (82) to rewrite (81) as follows

$$
\frac{\partial q}{\partial c}=\frac{\beta b\left(\pi_{1}+\pi_{2}\right)(1-b) q /(1-\beta)}{b u^{\prime \prime}(q) q+\left[\gamma-1-(1-b) i-\beta b\left(\pi_{1}+\pi_{2}\right)(1-b) c\right] /(1-\beta)}
$$

From the proof of Proposition 2 , in the case $\varepsilon+(1-b) c<\eta_{1}$ of a fully constrained equilibrium the denominator at the right-hand side in 83 is negative. Since in the fully constrained equilibrium $\ell_{h}=\ell_{f}^{\eta}=\ell$ for all $\eta$ and $\phi \ell=(1-b) q$ from (42), it follows that $\partial(\phi \ell) / \partial c<0$ for $c<\left(\eta_{1}-\varepsilon\right) /(1-b)$. Since $\partial q / \partial c<0$ for all $c<\left(\eta_{1}-\varepsilon\right) /(1-b)$ it follows that, in the case $\varepsilon=0, q$ and $(\phi \ell)$ are decreasing in $c$ up to $c=\eta_{1} /(1-b)$ and, in the case $\varepsilon>0, q$ and $\phi \ell$ are decreasing in $c$ up to $c=\left(\eta_{1}-\varepsilon\right) /(1-b)$.

Second, we show that the function $q=q(c)$ is not continuous. For this, we evaluate the function $q=q(c)$ at a particular value of $\gamma$ and infer that its properties hold for a range of values of $\gamma$. Consider the case $\varepsilon=0$. The function $q=q(c)$ jumps below at $c=\eta_{1} /(1-b)$; i.e., $q\left(c^{-}\right)>q\left(c^{+}\right)$with $c^{-}=\eta_{1} /(1-b)-d c$, $c^{+}=\eta_{1} /(1-b)+d c$ and $d c \rightarrow 0$. From (43) and (50), it follows that

$$
b\left[u^{\prime}\left(q\left(c^{-}\right)\right)+\pi_{1} \eta_{1}\right]+(1-b) i\left(c^{-}\right)=b u^{\prime}\left(q\left(c^{+}\right)\right)+(1-b) i\left(c^{+}\right)
$$

where $q\left(c^{-}\right)$and $i\left(c^{-}\right)$solve (45) and 43) (with $\hat{q}$ being determined by 444), whereas $q\left(c^{+}\right)$and $i\left(c^{+}\right)$solve (52) and (50) (with $\hat{q}$ being determined by (51)). 
At $\gamma=\gamma^{1}\left(c^{+}, \varepsilon=0\right)=1+\beta b \pi_{2}(1-b) c^{+}+b \pi_{1} \eta_{1}, i\left(c^{+}\right)=b \pi_{1} \eta_{1} /(1-b)$. Hence, at $\gamma=\gamma^{1}\left(c^{+}, \varepsilon=0\right)$ (84) becomes

$$
b u^{\prime}\left(q\left(c^{-}\right)\right)+(1-b) i\left(c^{-}\right)=b u^{\prime}\left(q\left(c^{+}\right)\right)
$$

Note that $\gamma^{1}\left(c^{+}, \varepsilon=0\right)>\gamma^{1}\left(c^{-}, \varepsilon=0\right)=1+\beta b\left(\pi_{1}+\pi_{2}\right)(1-b) c^{-}$provided that $\beta<1$. Thus, at $\gamma=\gamma^{1}\left(c^{+}, \varepsilon=0\right), i\left(c^{-}\right)>0$ since $i\left(c^{-}\right)=0$ at $\gamma^{1}\left(c^{-}, \varepsilon=0\right)$ and $\partial i / \partial \gamma>0$ in a fully constrained equilibrium with $c<\eta_{1} /(1-b)$ from Proposition 2. Hence, from (85) $q\left(c^{+}\right)<q\left(c^{-}\right)$. It follows that the function is discontinuous at $c=\eta_{1} /(1-b)$ with $q\left(c^{+}\right)<q\left(c^{-}\right)$. Since all functions in 84$)\left(u^{\prime}\left(q\left(c^{-}\right)\right)\right.$ and $i\left(c^{-}\right)$which solve (45) and 43), and $u^{\prime}\left(q\left(c^{+}\right)\right)$and $i\left(c^{+}\right)$which solve 52 ) and (50) $)$ are continuous, we can infer that there is a range of values of $\gamma$ for which the function $q=q(c)$ is not continuous at $c=\eta_{1} /(1-b)$ with $q\left(c^{+}\right)<q\left(c^{-}\right)$. From (42), it follows that at $c=\eta_{1} /(1-b)$ the function $\phi \ell$ also jumps below.

Similarly, in the case $\varepsilon>0$, the function $q=q(c)$ jumps below at $c=$ $\left(\eta_{1}-\varepsilon\right) /(1-b)$; i.e., $q\left(c^{-}\right)>q\left(c^{+}\right)$with $c^{-}=\left(\eta_{1}-\varepsilon\right) /(1-b)-d c, c^{+}=$ $\left(\eta_{1}-\varepsilon\right) /(1-b)+d c$ and $d c \rightarrow 0$. From (43) and (50), it follows that

$$
b\left[u\left(q\left(c^{-}\right)\right)+\pi_{1}\left(\eta_{1}-\varepsilon\right)\right]+(1-b) i\left(c^{-}\right)=b u\left(q\left(c^{+}\right)\right)+(1-b) i\left(c^{+}\right)
$$

where $q\left(c^{-}\right)$and $i\left(c^{-}\right)$solve (45) and (43) (with $\hat{q}$ being determined by (44)), whereas $q\left(c^{+}\right)$and $i\left(c^{+}\right)$solve (52) and (50) (with $\hat{q}$ being determined by (51)). At $\gamma=\gamma^{1}\left(c^{+}, \varepsilon>0\right)=1+\beta b \pi_{2}(1-b) c^{+}+b \pi_{1}\left(\eta_{1}-\varepsilon\right), i\left(c^{+}\right)=b \pi_{1}\left(\eta_{1}-\varepsilon\right) /(1-b)$. Hence, at $\gamma=\gamma^{1}\left(c^{+}, \varepsilon>0\right)$ becomes

$$
b u\left(q\left(c^{-}\right)\right)+(1-b) i\left(c^{-}\right)=b u\left(q\left(c^{+}\right)\right)
$$

At $\gamma=\gamma^{1}\left(c^{+}, \varepsilon>0\right), i\left(c^{-}\right)>0$ since $i\left(c^{-}\right)=0$ at $\gamma^{1}\left(c^{-}, \varepsilon>0\right), \partial i / \partial \gamma>0$ in a fully constrained equilibrium with $c<\left(\eta_{1}-\varepsilon\right) /(1-b)$ from Proposition 2, and $\gamma^{1}\left(c^{+}, \varepsilon>0\right)>\gamma^{1}\left(c^{-}, \varepsilon>0\right)$. Thus, from 87) $q\left(c^{+}\right)<q\left(c^{-}\right)$. It follows that the function is discontinuous at $c=\left(\eta_{1}-\varepsilon\right) /(1-b)$ with $q\left(c^{+}\right)<q\left(c^{-}\right)$. Since all functions in (86) are continuous, we can infer that there is a range of values of $\gamma$ for which the function $q=q(c)$ is not continuous at $c=\left(\eta_{1}-\varepsilon\right) /(1-b)$ with $q\left(c^{+}\right)<q\left(c^{-}\right)$. From 42 , it follows that the function $\phi \ell$ also jumps below at $c=\left(\eta_{1}-\varepsilon\right) /(1-b)$.

Third, we show that $q$ is decreasing in $c$ for $c>\eta_{1} /(1-b)$ in the case $\varepsilon=0$ and for $c>\left(\eta_{1}-\varepsilon\right) /(1-b)$ in the case $\varepsilon>0$. To prove that this increase in $c$ entails a decrease in credit in a fully constrained equilibrium in which $\varepsilon+(1-b) c>\eta_{1}$ with $\varepsilon \geq 0$, differentiate the borrowing constraint stated in 52 with respect to $c$ :

$$
\begin{aligned}
& -[(1-b) i+1] \frac{\partial q}{\partial c}-(1-b) q \frac{\partial i}{\partial c}-\frac{\beta b}{1-\beta} \pi_{2}(1-b) q \\
& +\frac{\beta b}{1-\beta}\left\{u^{\prime}(q)-1+\pi_{2}\left[\eta_{2}-\varepsilon-(1-b) c\right]\right\} \frac{\partial q}{\partial c}=0
\end{aligned}
$$


From 50 we get

$$
(1-b) \frac{\partial i}{\partial c}=-b u^{\prime \prime}(q) \frac{\partial q}{\partial c}
$$

Use (50) and (89) to rewrite (88) as follows

$$
\frac{\partial q}{\partial c}=\frac{\beta b \pi_{2}(1-b) q /(1-\beta)}{b u^{\prime \prime}(q) q+\left[\gamma-1-(1-b) i-\beta b \pi_{2}(1-b) c\right] /(1-\beta)}
$$

As shown in the proof of Proposition 2, in a fully constrained equilibrium in the case $\varepsilon<\eta_{1} \leq(1-b) c+\varepsilon<\eta_{2}$ the denominator at the right-hand side in (90) is negative, so $\partial q / \partial c<0$. Since in the fully constrained equilibrium $\ell_{h}=\ell_{f}^{\eta}=\ell$ for all $\eta$ and $\phi \ell=(1-b) q$ from (42), it follows that $\partial(\phi \ell) / \partial c<0$.

Finally, from Proposition 4 for $\varepsilon+(1-b) c<\eta_{1}$, in a fully constrained equilibrium $q$ and $\phi \ell$ are decreasing in $\varepsilon$. In addition, from Proposition 5 for $(1-b) c>\eta_{1}$, there is a range of values of $\gamma$ for which $q$ and $\phi \ell$ are increasing in $\varepsilon$. Then it is straightforward to verify that if $c$ increases from $c_{0}$ to $c_{1}$ and a fully constrained equilibrium exists for $c_{0}$ and $c_{1}$ for this range of values of $\gamma$, the decrease in $q$ and $\phi \ell$ is stronger in the case $\varepsilon=0$ than in the case $\varepsilon>0$.

Differentiating (66) with respect to $c$ yields

$$
\begin{aligned}
\frac{\partial \mathcal{W}}{\partial c}\left(\frac{b}{1-\beta}\right)^{-1} & =\left\{u^{\prime}(q)-1+\pi_{1} \eta_{1}+\pi_{2} \eta_{2}-\left(\pi_{1}+\pi_{2}\right)[\varepsilon+(1-b) c]\right\} \frac{\partial q}{\partial c} \\
& -\left(\pi_{1}+\pi_{2}\right)(1-b) q
\end{aligned}
$$

Thus $\partial \mathcal{W} / \partial c>0$ for all $(1-b) c<\eta_{1}-\varepsilon$ since $\partial q / \partial c<0$ for $(1-b) c<\eta_{1}-\varepsilon$. Similarly, after differentiating (75) it is straightforward to verify that $\partial \mathcal{W} / \partial c<0$ for all $\varepsilon<\eta_{1} \leq(1-b) c+\varepsilon<\eta_{2}$ since $\partial q / \partial c<0$ in this case as well. Further, since $q\left(c^{+}\right)<q\left(c^{-}\right)$for $c^{-}=\left(\eta_{1}-\varepsilon\right) /(1-b)-d c, c^{+}=\left(\eta_{1}-\varepsilon\right) /(1-b)+d c$ and $d c \rightarrow 0$, comparison of (66) and $(75)$ demonstrates that welfare at $c^{+}$is lower than welfare at $c^{-}$. 


\section{References}

Acharya, V. V. and S. Steffen. 2013. "The Greatest Carry Trade Ever? Understanding Eurozone Bank Risks." Mimeo.

Aglietta, M. and L. Scialom. 2003. "The Challenge of European Integration for Prudential Policy." Financial Market Group Special Paper, London School of Economics.

Aguiar, M., M. Amador, E. Farhi, and G. Gopinath. 2014. "Coordination and crisis in monetary unions." NBER Working Paper No 20277.

Aiyagari, S. N. and S. Williamson. 2000. "Money and dynamic credit arrangements with private information." Journal of Economic Theory 91:248-279.

Alesina, A. and R. J. Barro. 2002. "Currency unions." Quarterly Journal of Economics 117:409-436.

Andolfatto, D. 2010. "Essential interest-bearing money." Journal of Economic Theory 145:1495-1507.

Barro, R. J. and D. B. Gordon. 1983. "Rules, discretion and reputation in a model of monetary policy." Journal of Monetary Economics 12:101-121.

Beck, T., editor. 2012. Banking Union for Europe: Risks and Challenges. Vox eBook.

Beetsma, R. and M. Giuliodori. 2010. "The macroeconomic costs and benefits of the EMU and other monetary unions: An overview of recent research." Journal of Economic Literature 48:603-641.

Beetsma, R. and H. Uhlig. 1999. "An Analysis of the Stability and Growth Pact." Economic Journal 74:546-571.

Bencivenga, V. and G. Camera. 2011. "Banking in a matching model of money and capital." Journal of Money, Credit and Banking 43:449-476.

Benigno, P. 2004. "Optimal Monetary Policy in A Currency Area." Journal of International Economics 63:293-320.

Berentsen, A., G. Camera, and C. Waller. 2007. "Money, Credit and Banking." Journal of Economic Theory 135 (1):171-195.

Bertay, A. C., A. Demirguç-Kunt, and H. Huizinga. 2011. "Is Financial Safety Net a Barrier to Cross-Border Banking?" European Bnaking Center Discussion Paper 2011-037.

Chari, V.V. and P.J. Kehoe. 2007. "On the need for fiscal constraints in a monetary union." Journal of Monetary Economics 54 (8):2399-2408. 
Claessens, S. and N. van Horen. 2012. "Foreign Banks: Trends, Impact and Financial Stability." IMF Working Paper.

Cooley, T. and V. Quadrini. 2003. "Common Currencies vs. Monetary Independence." Review of Economic Studies 70:785-806.

Cooper, R. and H. Kempf. 2003. "Commitment and the Adoption of a Common Currency." International Economic Review 44 (1):119-142.

. 2004. "Overturning Mundell: fiscal policy in a monetary union." Review of Economic Studies 71:371-396.

Cooper, R., H. Kempf, and D. Peled. 2010. "Regional debt in monetary unions:Is it inflationary?" European Economic Review 54:345-358.

Corbae, D. and J. Ritter. 2004. "Decentralized credit and monetary exchange witwith public record keeping." Economic Theory 24:933-951.

Davis, L. 1965. "The Investment Market, 1870-1914: The Evolution of a National Market." Journal of Economic History 25:355-399.

De Grauwe, P. 2013. "The European Central Bank as Lender of Last Resort in the government bond markets." CESifo Economic Studies 59:520-535.

De Haas, R. and I. van Lelyveld. 2010. "Internal Capital Markets and Lending by Multinational Bank Subsidiaries." Journal of Financial Intermediation 19:1-25.

Dixit, A. and L. Lambertini. 2001. "Monetary-fiscal interactions and commitment versus discretion in a monetary union." European Economic Review 45:977-987.

Djankov, S., O. Hart, C. McLiesh, and A. Shleifer. 2008. "Debt Enforcement around the World." Journal of Political Economy 116:1105-49.

Dornbusch, R. 1997. "Fiscal aspects of monteray integration." American Economic Review 87:221-223.

ECB. 2007. "Financial Integration in Europe." Tech. rep.

—. 2012. "Financial Integration in Europe." Tech. rep.

Eichengreen, B. 2007. "The breakup of the Euro area." NBER working paper 13393.

Gali, J. and T. Monacelli. 2008. "Optimal monetary and fiscal policy in a currency union." Journal of International Economics 75:116-132.

Geromichalos, A. and I. Simonovska. 2014. "Asset Liquidity and International Portfolio Choice." Journal of Economic Theory 151:342-380. 
Gertler, M. and N. Kiyotaki. 2007. "Financial Intermediation and Credit Policy in Business Cycle Analysis." In Handbook of Monetary Economics, vol. 3A, edited by B. Friedman and M. Woodford. Amsterdam: Elsevier, 48-54.

Goodhart, C. 2011. "Global macroeconomic and financial supervision: Where next?" NBER Working Paper No 17682.

Gropp, R. and A. Kashyap. 2009. "A New metric for banking integration in Europe." NBER Working Paper 14735.

Gros, D. 2012. "The Single European Market in Banking in decline - ECB to the rescue?" In Banking Union for Europe. Risks and challenges, edited by T. Beck. Vox eBook, 51-55.

Hartmann, P., A. Maddaloni, and S. Manganelli. 2003. "The euro area financial system: structure, integration and policy initiatives." Oxford Review of Economic Policy 19 (1):180-213.

Houston, J. F., C. Lin, and Y. Ma. 2012. "Regulatory Arbitrage and International Bank Flows." 62:1845-95.

Hu, T. W., J. Kennan, and N. Wallace. 2009. "Coalition-proof trade and the Friedman rule in the Lagos-Wright model." Journal of Political Economy 117:116137.

James, J. A. 1976. "The Evolution of the National Money Market, 1888-1911." The Journal of Economic History 36:878-897.

James, J. A. and D. F. Weiman. 2010. "From Drafts to Checks: The Evolution of Correspondent Banking Networks and the Formation of the Modern U.S. Payments System, 1850-1914." Journal of Money, Credit and Banking 42 (23):237-265.

Jentzsch, N. 2007. "Do we need a European Directive for Credit Reporting?" In CESifo DICE Report, vol. 5, edited by Ifo Institute for Economic Research. $48-54$.

Jentzsch, N. and A. San José Rientra. 2003. "Information Sharing and Its Implications for Consumer Credit Markets: United States vs. Europe." mimeo.

Jochem, A. and U. Volz. 2011. "Portfolio holdings in the euro area - home bias and the role of international, domestic and sector-specific factors." Bundesbank Discussion Paper Economic Studies 07.

Kalemli-Ozcan, S., E. Papaioannou, and J.-L. Peydró. 2010. "What lies beneath the euro's effect on financial integration? Currency risk, legal harmonization, or trade?" Journal of International Economics 81:75-88. 
Kenen, P. 1969. "The theory of Optimal Currency Areas: An eclectic view." In Monetary Problems of the International Economy, edited by R.A. Mundell and A.K. Swoboda. Chicago Unisversity Press.

Kiyotaki, N. and J. Moore. 2003. "A Cost of Unified Currency." In Central Banking, Monetary Theory and Practice: Essays in Honour of Charles Goodhart, edited by P. Mizen. Edward Elgar Publishing.

Kleimeier, S. and H. Sander. 2007. "Integrating Europe retail banking markets: Where do we stand?" Tech. rep., Centre for European Policy Studies.

Kocherlakota, N. R. 2002. "The two-money theorem." International Economic Review 43:333-346.

Kocherlakota, N. R. and T. Krueger. 1999. "A Signaling Model of Multiple Monies." Review of Economic Dynamics 2:231-244.

Lagos, R. and R. Wright. 2005. "A Unified Framework for Monetary Theory and Policy Evaluation." Journal of Political Economy 113 (3):463-484.

Liu, Q. and S. Shi. 2010. "Currency Areas and Monetary Coordination." International Economic Review 51 (3):813-836.

Manna, M. 2011. "Home Bias in Interbank lending and banks' resolution regimes." Bank of Italy working papers "Temi di Discussione' 816.

Matsuyama, K., N. Kiyotaki, and A. Matsui. 1993. "Toward a Theory of International Currency." Review of Economic Studies 60:125-140.

Milesi-Ferreti, G.M. and C. Tille. 2011. "the great retrenchment: international capital flows during the global financial crisis." Economic Policy 26:289-346.

Miron, J.A. 1986. "Financial Panics, the Seasonality of the Nominal Interest Rates and the founding of the Fed." American Economic Review 76:125-140.

Mongelli, F. P. 2002. "“New" views on the optimum currency area theory: What is EMU telling us?" ECB Working Paper No 138.

Mundell, R. 1961. "A Theory of Optimum Currency Areas." American Economic Review 51:657-665.

Mundell, R.A. 1973. "Uncommon arguments for common currencies." In The economics of common currencies, edited by H.G. Johnson and A.K. Swoboda. Harvard University Press.

Nieto, M. J. and E. N. White. 2013. "Will bank supervision in Ohio and Austria be similar? A transatlantic view of the Single Supervisory Mechanism." Column. URL http://www . voxeu.org/. 
Peek, J. and E.. Rosengren. 1997. "The International Transmission of Financial Shocks: The Case of Japan." American Economic Review 87:495-505.

Popov, A. and G.. Udell. 2012. "Cross-border banking, credit access, and the financial crisis." Journal of International Economics 87:147-161.

Ravikumar, B. and N. Wallace. 2001. "A Benefit of Uniform Currency?" manuscript, Pennsylvania State University.

Rocheteau, G. and R. Wright. 2005. "Money in search equilibrium, in competitive equilibriu, and in competitive search equilibrium." Econometrica 73:175-202.

Rockoff, H. 1990. "The "Wizard of Oz" as a monetary allegory." Journal of Political Economy 98:737-760.

. 2003. Monetary Unions: Theory, History, Public choice, chap. How Long Did it Take the United States to Become an Optimal Currency Area. Routledge, 70-103.

Rolnick, A., B. D. Smith, and W. E. Weber. 2003. "Establishing a monetary union in the United States." In Evolution and Procedure in Central Banking, edited by D. Altig and B. D. Smith. Cambridge University Press, 227-255.

Rousseau, P. L. 2013. "Politics on the Road to the U.S. monetary union." Vanderbilt University Department of Economics Working Papers 13-00006.

Sargent, T. 2012. "United States then, Europe now." Journal of Political Economy 120:1-40.

Sargent, T. J. and N. Wallace. 1981. "Some unpleasant monetary arithmetic." Federal Reserve Bank of Minneapolis Quarterly Review, 5:1-17.

Schoenmaker, D. and T. Bosch. 2008. "Is the home bias in equities and bonds declining in Europe?" Investment Management and Financial Innovations 5:90102 .

Sims, Christopher. 2013. "Paper Money." American Economic Review 103:563-84.

Sørensen, C. L. and J. M. P. Gutiérrez. 2006. "Euro area banking sector integration: using hierarchical cluster analysis techniques." ECB Working Papers 627.

Sylla, R. 1969. "Federal Policy, Banking Market Structure and Capital Mobilization in the United States, 1863-1913." The Journal of Economic History 29 (4):657-686.

Trejos, A. 2004. "International Currencies and Dollarization." In Evolution and Procedures in Central Banking, edited by D. Altig and B. Smith. Cambridge University Press. 
White, E. N. 1982. "The Political Economy of Banking Regulation, 1864-1933." Journal of Economic History 42:33-40.

Wright, R. and A. Trejos. 2001. "International Currency." Advances in Macroeconomics 1 (1).

Zhang, C. 2014. "An Information-Based Theory of International Currency." Journal of International Economics 93:286-301. 